\title{
Indicators of the Mosque as a Social Type
}

\author{
Zainab Huseen Ra'ouf
}

Department of Architecture, University of Technology, Baghdad, Iraq

\section{z_alobaidi@yahoo.com}

\begin{tabular}{|l|l|l|}
\hline Submission date:- 5/2/2019 & Acceptance date:- 28/4/2019 & Publication date:-15/5/2019 \\
\hline
\end{tabular}

\begin{abstract}
:
Sustainability emerged as a general trend in architecture within its dimensions (environmental, economic, and social) which affected on certain types of buildings especially the modern mosque architecture. The social dimension of sustainability represents the area of research interest, as it does not show the extent of its influence in determining the design characteristics of the mosque's architecture. hence, the research problem was (lack of knowledge perception of the mosque indicators that make it a social type and the absence of a clear vision of the vocabulary most achieved in local modern mosque as well as the nature of the criteria that determines the acceptance of this type of mosques within the local community).According to this the research goals are (Identify the indicators that characterize the mosque as a social type, determine the nature of the most achieved indicators within the local model, determine the index nature of the collective acceptance for this building type.)

The research determined the indicators that characterised mosque as social type and found that they are related to the indicators related to making place and living occupancy of social sustainability. These affected on layout, spatial organization and formal aspects of mosque.

The local mosque achieved these indicators partially and its design was closer to the model of the social mosque within its vocabulary which was reflected within layout and spatial aspect as it was more accomplished.as well as The research concluded that the cultural background and the living level of the recipient represent the nature of the indicator that responsible for common acceptance for this type although it does not represent a new type of mosques, but represent an extension of the comprehension functional role of the Prophet's Mosque.
\end{abstract}

Keywords: Social Sustainability, Contemporary Mosque Architecture, Social type of Mosques, Local Mosque Building. 


\section{مؤشر ات المسجد كنمط اجتماعي \\ زينب حسين روئوف \\ قسم هندسة العدارة، الجامعة التكنولوجية، بغداد -العراق}

\section{$\underline{\text { z alobaidi@yahoo.com }}$}

برزت الاستدامة كتوجه عام أثر في حقل العمارة ضمن ابعاده (الييئية، الاقتصادية، الاجتماعية). أثز هذا التوجه في انماط

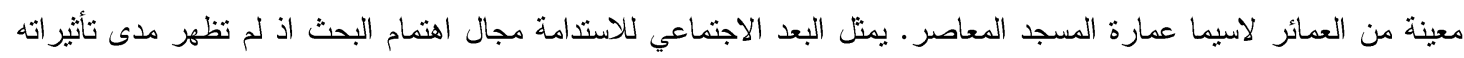

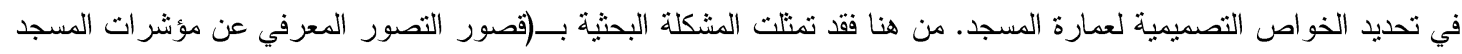

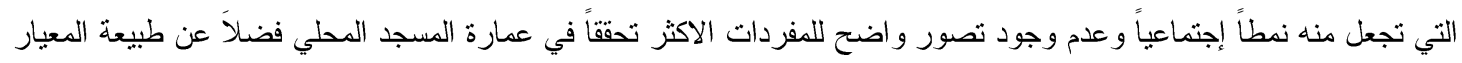

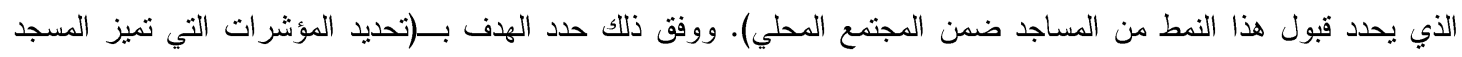

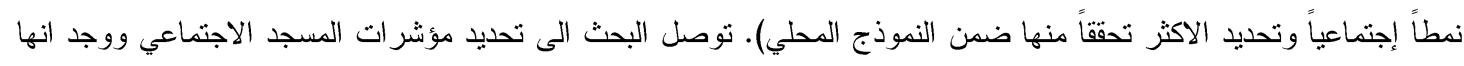

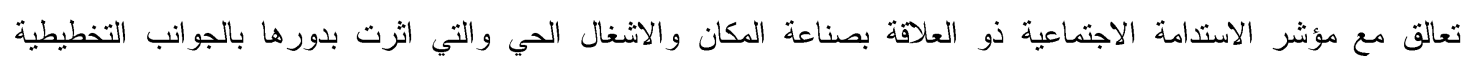

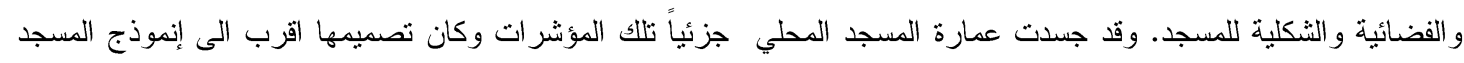

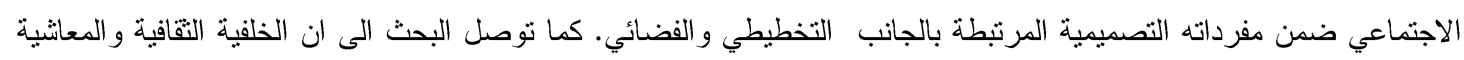

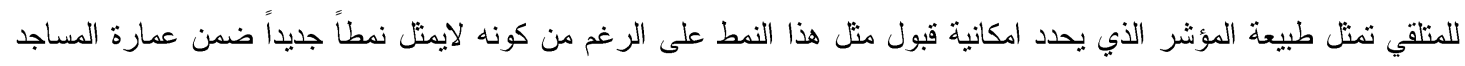
المعاصرة و انما تمتل امتداداً للدور الوظيفي للمسجد النبوي.

الكلمات الدالة: الاستدامة الاجتماعية، عمارة المسجد المعاصر، مؤشرات النمط الاجتماعي للمساجد، عمارة المسجد المحلي.

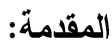

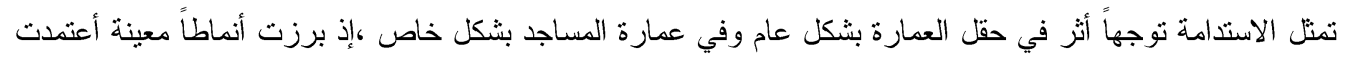

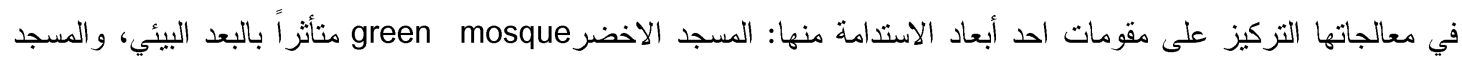

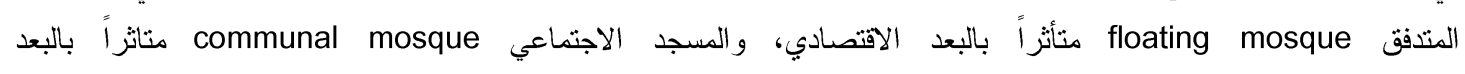

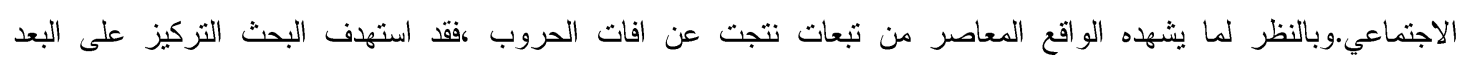

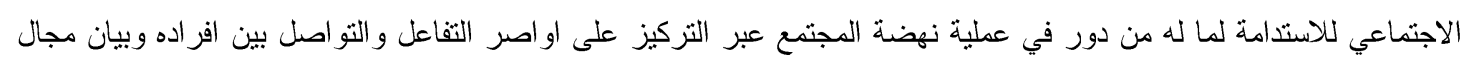

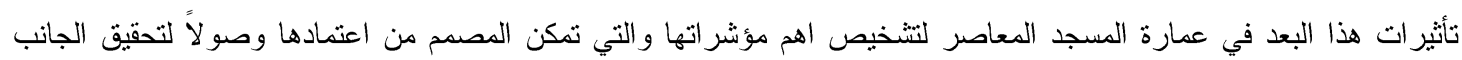

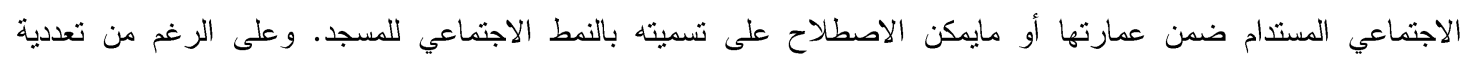

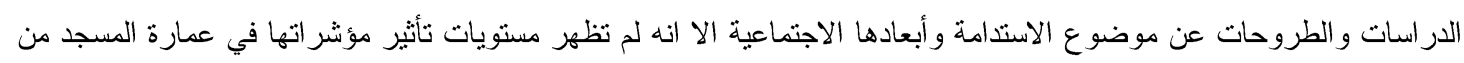

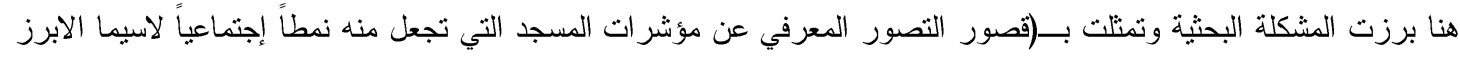

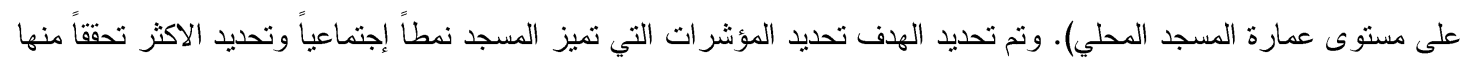

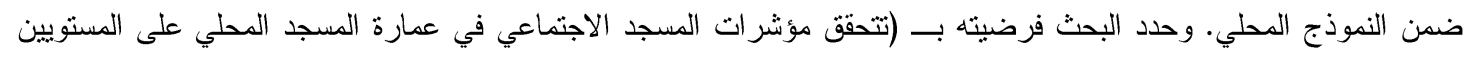

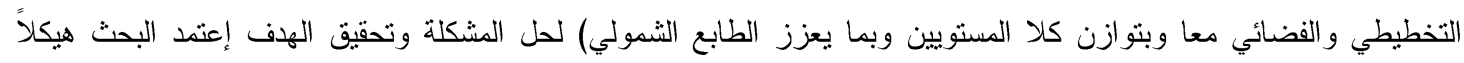
تضمن عدة محاور شملت:

المحور العام: ويختص بتقصي البعد الاجتماعي للاستدامة فضلاً عن عمارة المسجد المعاصر والمستويات المنعلقة بها. المحور العام: ويختص بتقصي البعد الاجتماعي للاستدامة فضلاً عن عمارة المسجد المعاصر و المستويات المتعلقة بها. المحور الخاص: الاستدامة الاجتماعية ضمن عمارة المسجد المعاصر . 
تعرف الاستدامة بـ(كل ما نحتاحه لبقائنا و العيش برفاهية سواء بشكل مباشر او غير مبانشر في بيئتا الطييعية مع الحفاظ

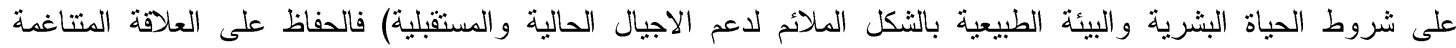
والمتجانسة بين الانسان والطبيعة يعد مبدأ اساسي لها. وشملت الاستدامة اعتبارات منعددة تنعلق بالبعد البيئي والاقتصادي لإئي

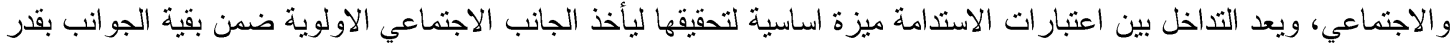

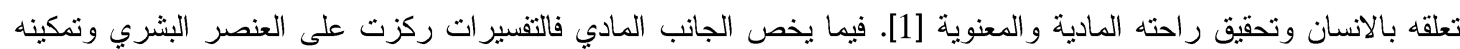

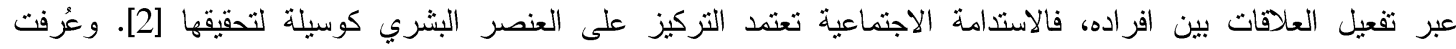

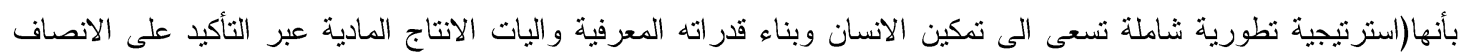

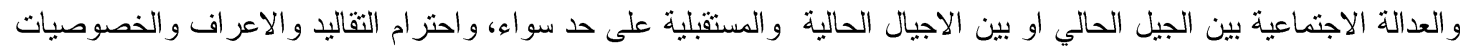

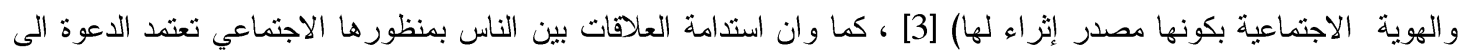

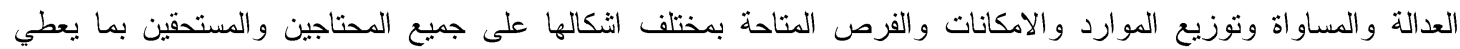

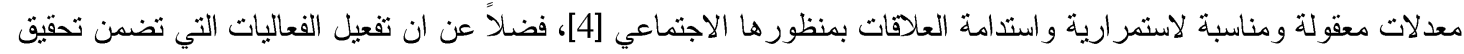

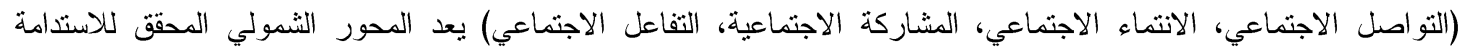

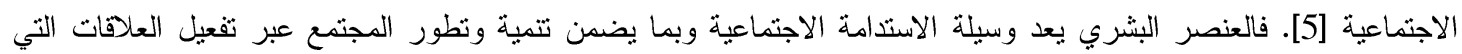

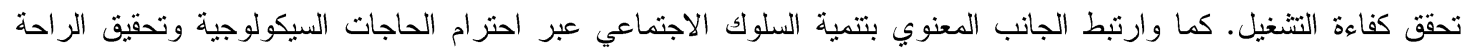

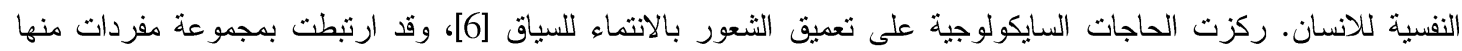

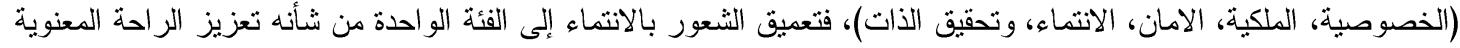

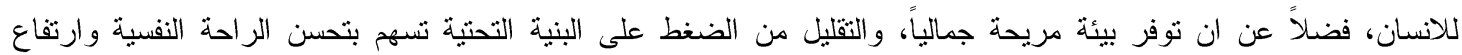

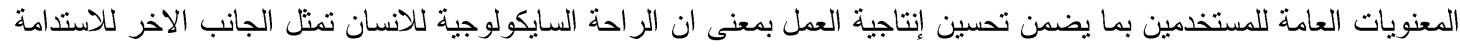
الاجتماعية الذي يضمن تحسين انتاجية العمل وزيادة الاتناج[7].

أكد ماسبق أن الطروحات المتعلقة بالاستدامة الاجتماعية تؤكد على الانسان كقيمة عليا ضمن المجتمع تتعلق مبادئها بتليية حاجاته المادية والسايكولوجية وبما يحقق مجتمع مستدام يحث العلاقات المستمرة بين افراده وبما يضمن كفاءة النتشغيل (الاتشغال الكفوء) وزيادة الاتتاج (الاشثغال الحي).

\section{1-2-2 الاستدامة الاجتماعية في العمارة:}

ارتبط تفسير الاستدامة الاجتماعية في العمارة بعدة طروحات، منها نعلق بتعزيز الطابع الثمولي كهدف اساسي للبناء عبر

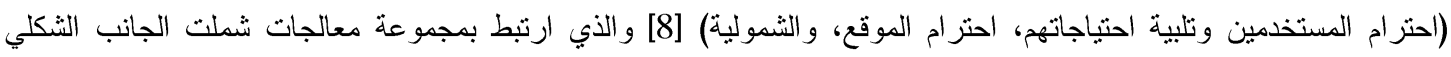
و التخطيطي والفضائي. وركزت طروحات اخرى بتفسير اتها على الكيفية وأكدت العلاقة مع السياق المحيط معمارياً وإجتماعياً

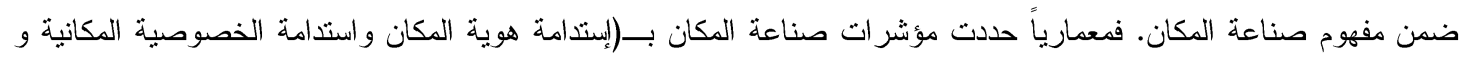

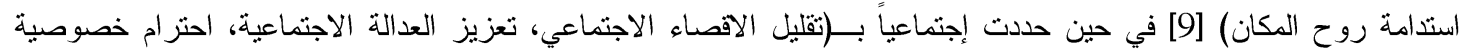

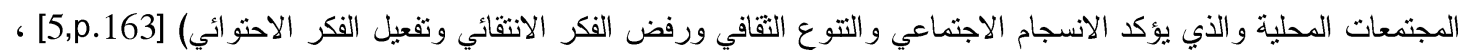

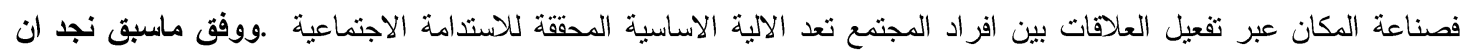

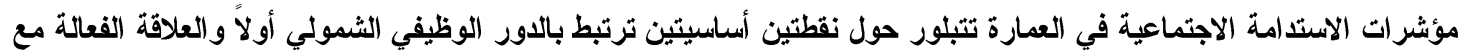
السياق ثانياً و كما يوضح جدول(1). 


\begin{tabular}{|c|c|c|}
\hline \multicolumn{3}{|c|}{ جدول 1 يوضح ابعاد الاستدامة الاجتماعية (اعداد الباحث) } \\
\hline الدور أو الوظيفة الثاملة للمسجد & الاشتغال الكفوء & \\
\hline الدور الفعال عبر العلاقة الحيوية مع السياق المحيط & الاشغال الحي & الاستدامة الاجتماعية في \\
\hline
\end{tabular}

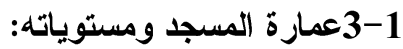

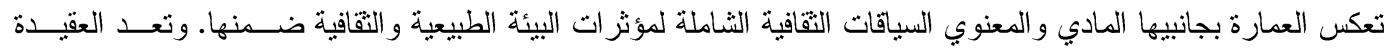

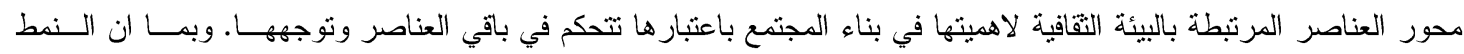

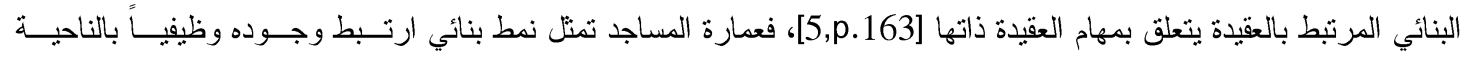

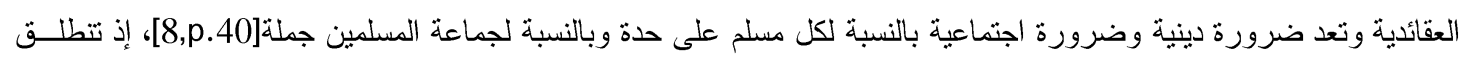

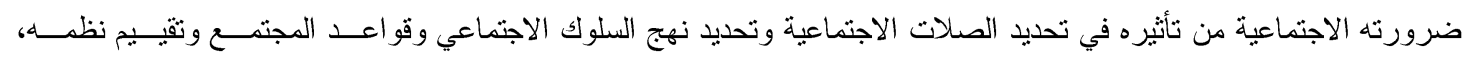

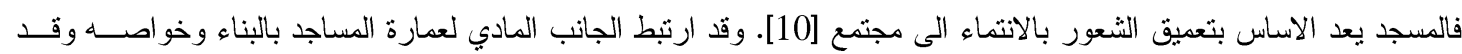

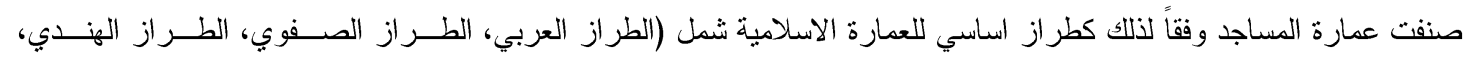

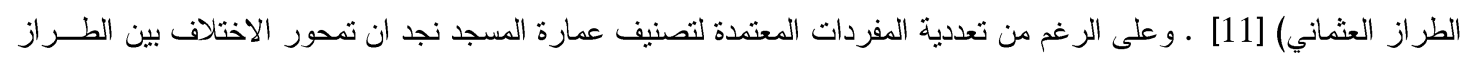

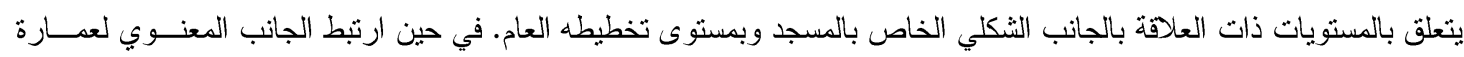

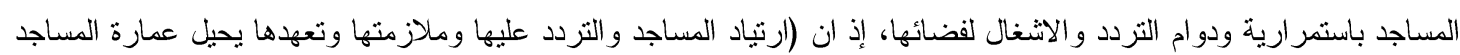

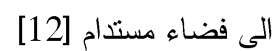

ووفقاً لما سبق فالوجود المادي المرتبط بــعمارة المسجد يتعلق بـــالمستوى التخطيطي، المستوى الثكلي) بينما الوجود

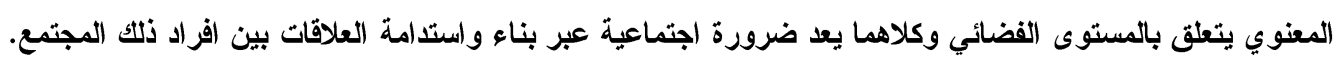

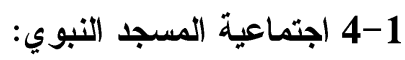

يمثل المسجد قيمة هامة في تتظيم التفاعلات في المجتمعات الإنسلامية. فهو مركز ترابط الجماعة الإسلامية وهيكلها المادي

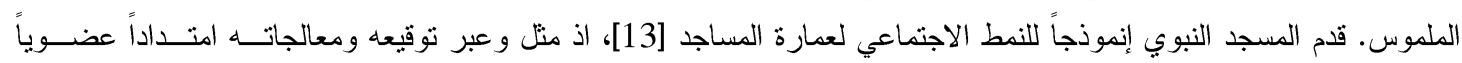

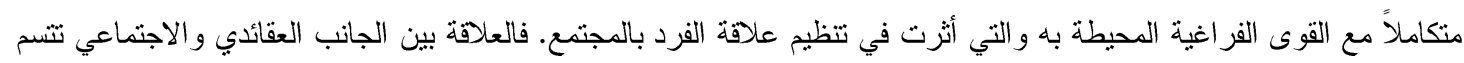

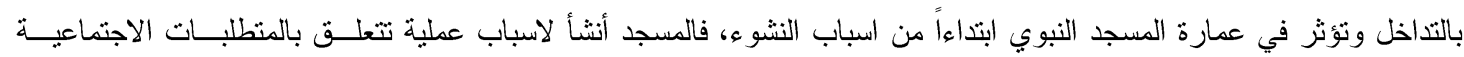

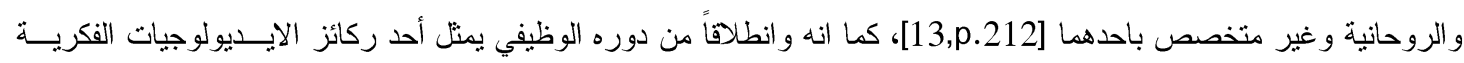

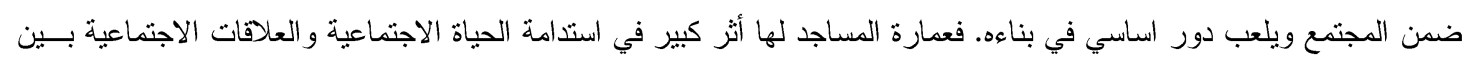

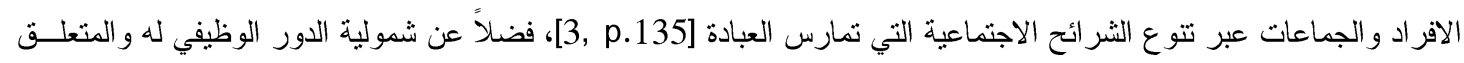

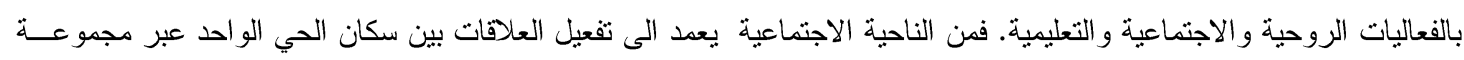

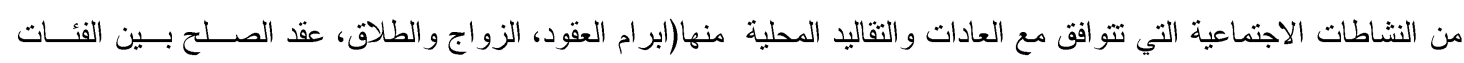

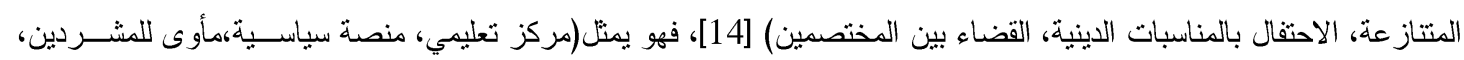

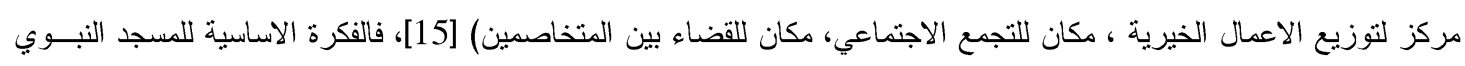

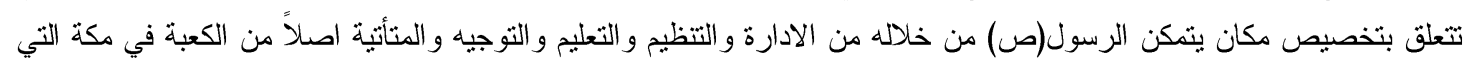

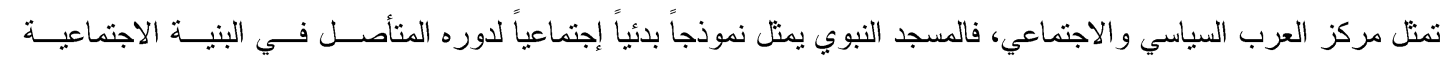

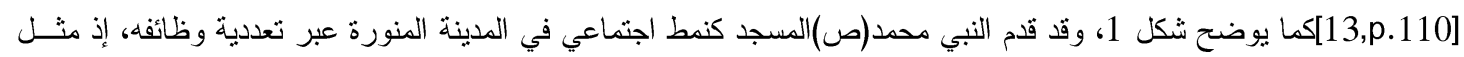

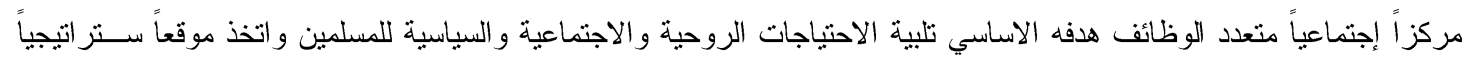

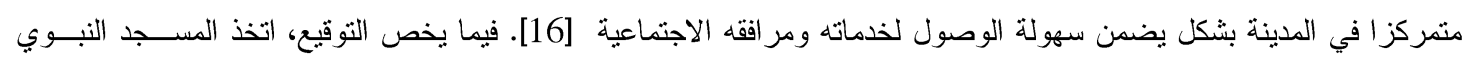

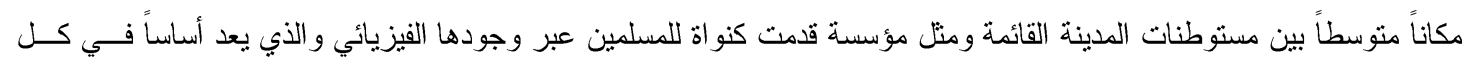

تطوير وبناء وتخطيط مستقبلي[17]. 


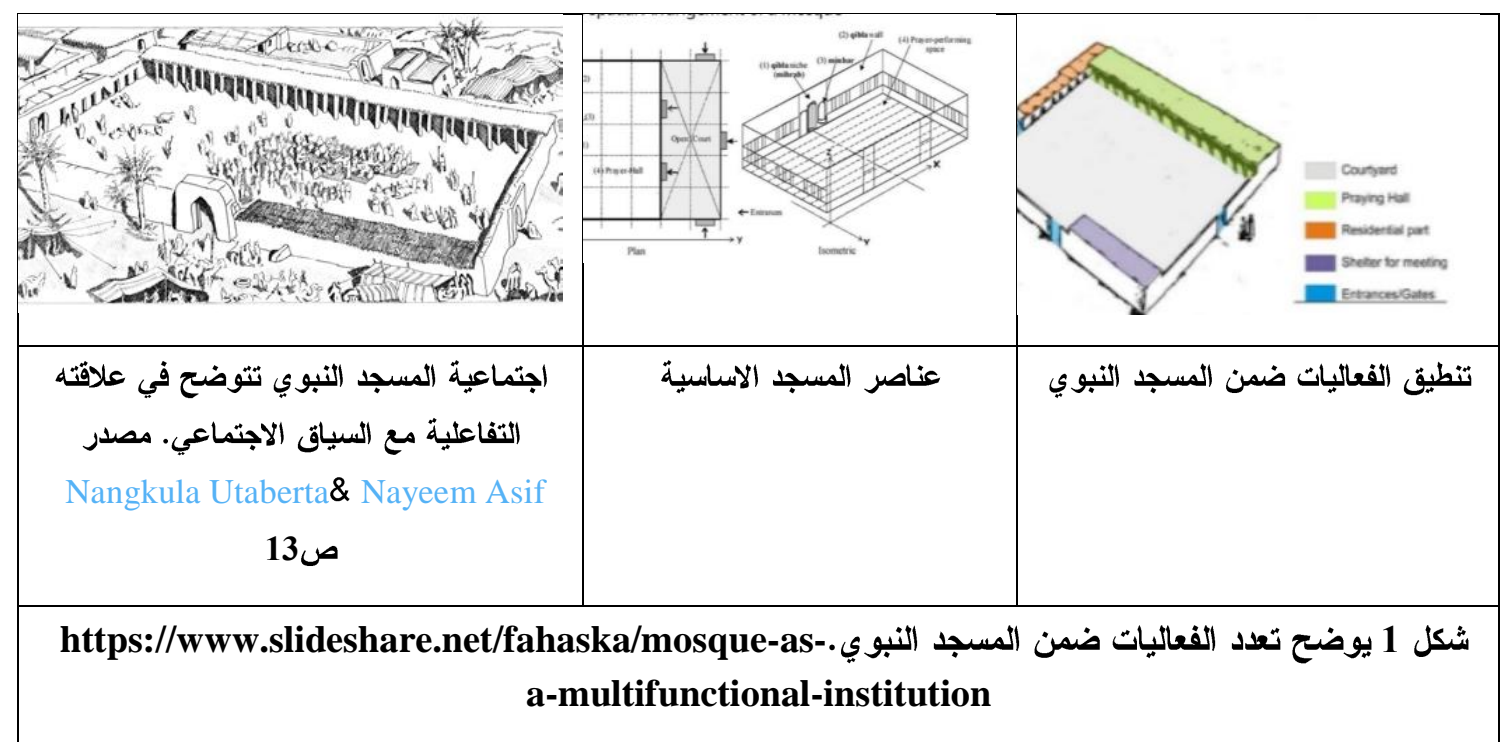

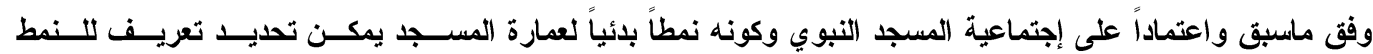

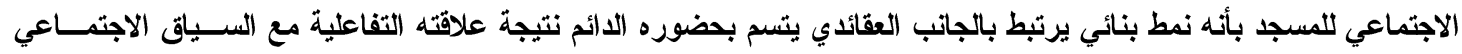

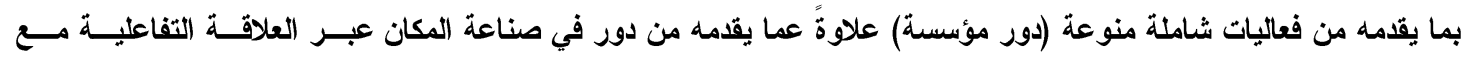

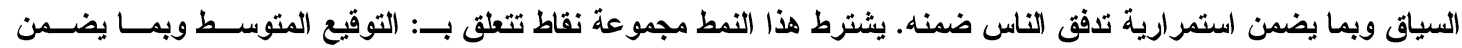
سهولة الوصول/تنوع وتعددية الوظائف/ مرونة الاستخدام. يتبين بروز بعض مؤشرات النمط الاجتماعي للمسجد ولتعزيـز هـذأه

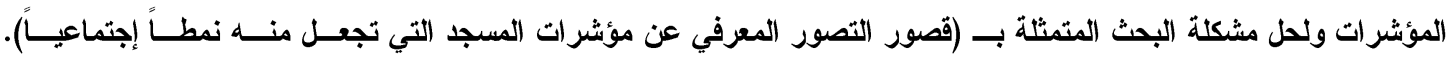

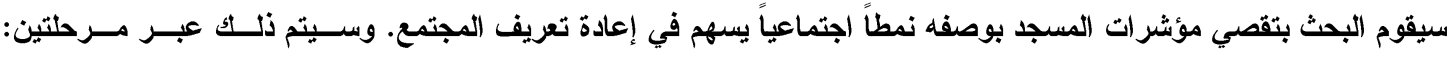

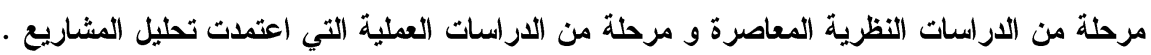

2-المحور الخاص

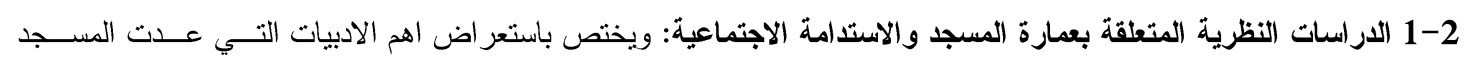
نمطاً اجتماعياً بشكل ضمني او مباشر و اعتمدت مؤشرات الاستدامة الاجتماعية كعامل اساسي في بلورة خصائصها.

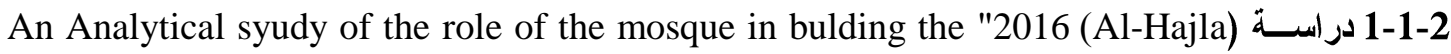
" social nociation in the Islamic city

تعالقت هذه الدر اسة مع الاستدامة الاجتماعية عبر التركيز على دور المسجد كمؤسسة اجتماعية تمثل وجهة تتظيم التفاعـل التهل

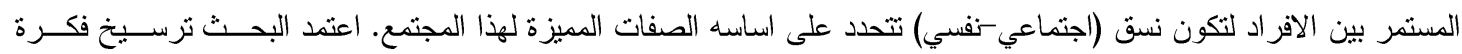

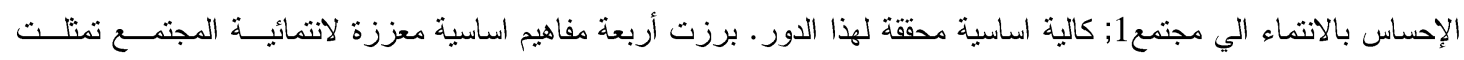

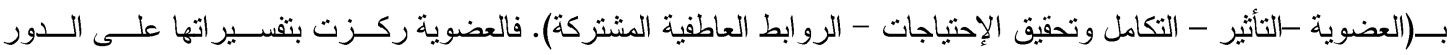

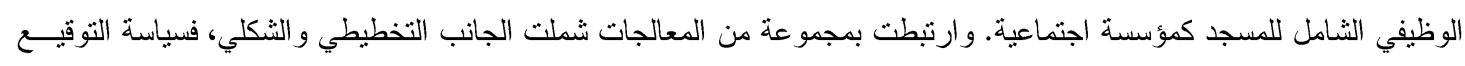
الخاصة بالمسجذمن مركز الفعاليات الحيوية والاكتظاظ يضمن استمر ارية التدفق البشرب وبما يحقق العلاقة الكفوءة مع الســياق.

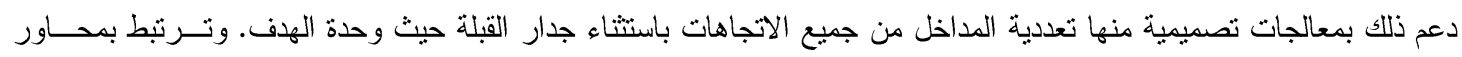
حركية تضمن سهولة الوصول الخاصة له. كما ارتبط تفسير (التكامل وتحقيق الاحتياجات) و (التأثير و الروابط العاطفية المثــتركة)

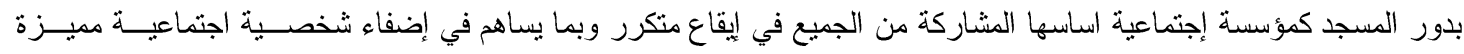

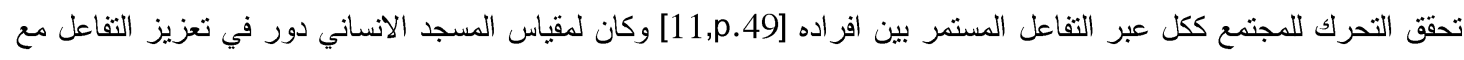

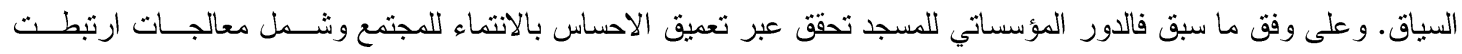

1 يقوم كلا من (McMillan \& Chavis) بتعريف "الإحساس بالانتماء إلى المجتمع" باعتباره "هو احساس ينتاب اعضاء المجتمع بالانتماء اليه

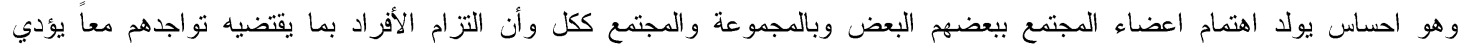

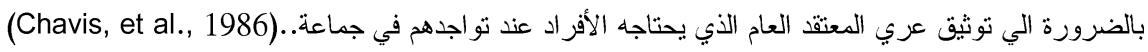


بالجانبين التخطيطي و الثنكلي، ركز الجانب التخطيطي على تكاملية العلاقة مع السياق كمفردة اساسية وتحققت عبر سياسة التوقيـع

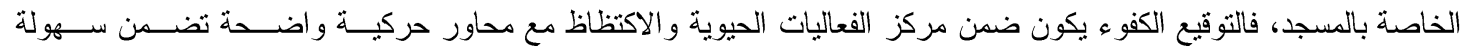
الوصول، كما برزت تعددية المداخل بكافة الاتجاهات باستثناء جدار القبلة كمعالجة شكلية تضمن تحقيق تكاملية العلاقة مع الســـاق. بينما ركز الجانب الفضائي الوظيفي على استحداث فعاليات تضمن الايقاع المنكرر وبما يعزز العلاقة التفاعلية بين الافراد وعـزـز ذلك بالمقياس الانساني للمسجد كمعالجة شكلية.

Rethinking the mosque in the modern " 2014 (M.Tajuddin\&M.Rashid) 2-1-2 دراسة 2-2 " muslim society

طرحت الدر اسة نموذجاً خاصاً للمسجد يتسم بحضوره الدائم نتيجة علاقته التفاعلية مع السياق الاجتماعي ويعتمد برنامجـاً

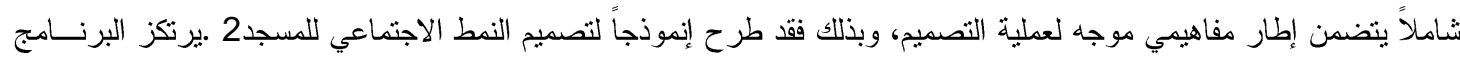

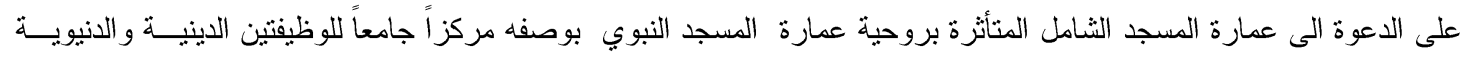

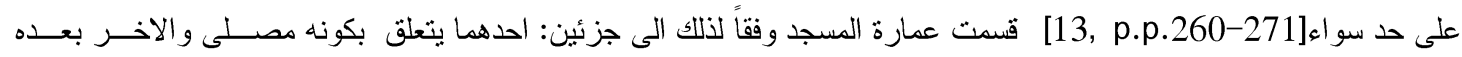

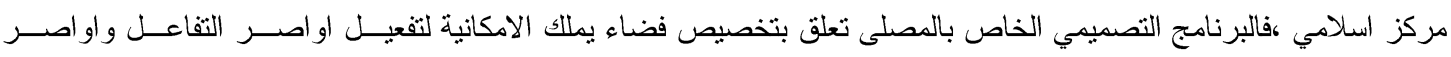

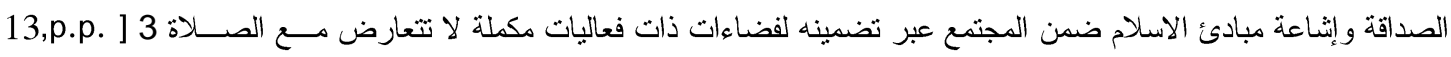

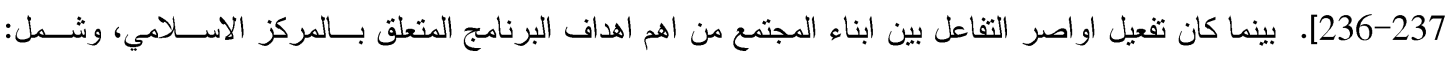
البرنامج التعليمي وله الاولوية لاهمية الدور التربوي في صناعة الحياة عبر الانعاش الاجتماعي للامم، البرنامج الاجنماعي ويقترح

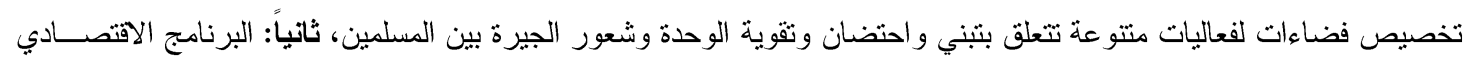

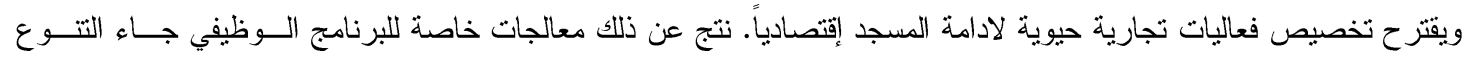
الفضائي جو اباً لها شملت الجانب التصميمي للمسجد فضلاً عن التخطيط والثكل. حيث صنفت الفضاءات الى اربعة انماط اساسـية لئة

-الفضاء الخاصة بالصلاة: ويشترط شموله المحر اب و المنبر .

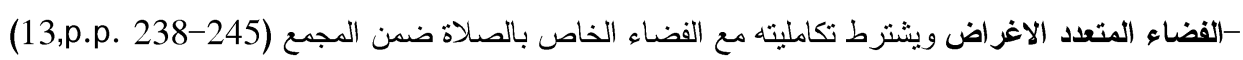

-الفضاء المتخصص بوظيفة محددة: ويتعلق بمصلى النساء و المكتبة واماكن الوضوء [13, p.p.246-247] - فضاءات تعمد الى إدامة المسجد اقتصادياً: تعد من أولويات تفعيل المسجد وتحقيق كفاءة التشغيل إذ تعد عامل جذب لزئل لزيارة

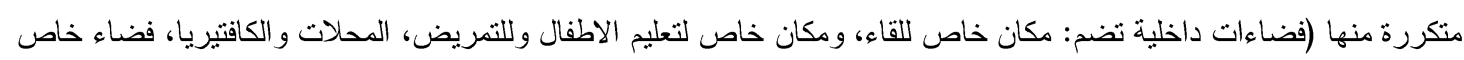
لورش عمل تدرييية، فضاءات خارجية: تنتوع بين مساحات مبلطة واماكن خاصة بلعب الاطفال ومساحات مؤثثة لتتجيع المسلمين لقضاء وقت جميل وممتع). فللمجد دور في تتظيم وتطوير المجتمع. كما أكدت الدراسة ان التوقيع ضمن مراكز الاكتظاظ

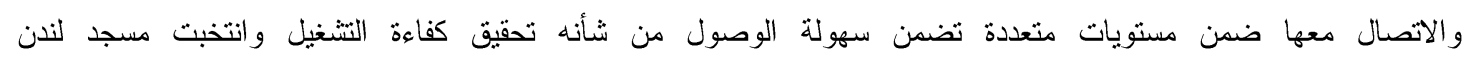

المركزي(شكل2) إنموذجاً محققاً لكل ماسبق [13: p.p.248-249.

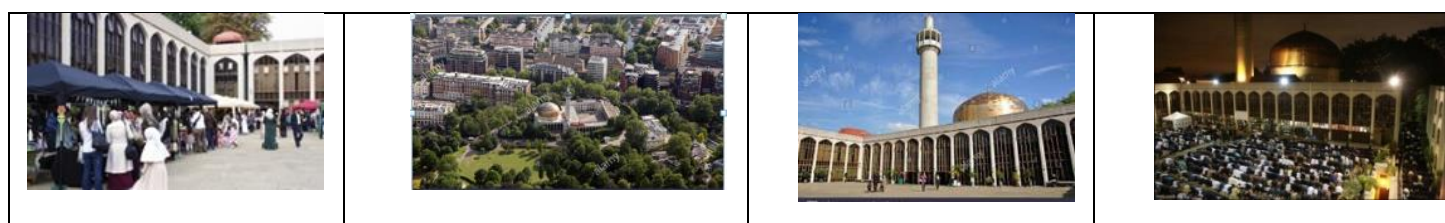

شكل2 مسجد لندن المركزي ويعد إنموذجاً مثالياً للنمط الاجتماعي للمساجد حسب الارسة

ووفث ماسبق نستخلص ان الثمولية تعد السمة الاساسية للنمط الاجتماعي للمسجد ويعنمد برنامجاً تصميمياً خاصاً قسم المسجد بموجبه الى جزأين اساسيين (مصلى مرتبط بالفعاليات الاينية ومركز اسلامي مختص بالفعاليات الانيوية). وارتبط بمجموعة من

2 حسب منت تحديده سابقاً من تعريف 2 3 منها (اماكن اللقاء والاكل في فنترة الانتظار لفعالية الصلاة، اماكن للقر اءة الصوتية والمرئية، اماكن للاسترخاء عبر التلاعب الضوئي تخفف من

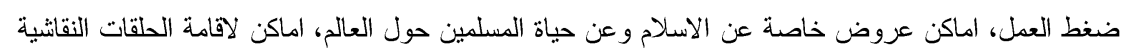


معالجات تخص الجاتب التخطيطي والفضائي. ارتبطت مفردات الجانب التخطيطي ب (التوقيع، الحجم). بينما التنوع الوظيفي الفضائي جاء محققاً للتفاعل و المشاركة والتو اصل المتعلقة بصناعة المكان.

REVIEW ON SUSTAINABLE ،2016، Nangkula Utaberta \& Nayeem Asifä3-1-2 دراسة AND INNOVATIVE APPROACH TOWARDS MOSQUE DESIGN IN CONTEMPORARY WORLD

أكدت الدراسة ان الاستدامة كمفهوم تمثل جوهر الايديولوجية الفكرية للمسلمين قدر تعلق الجانب الاجتماعي منها بتليية

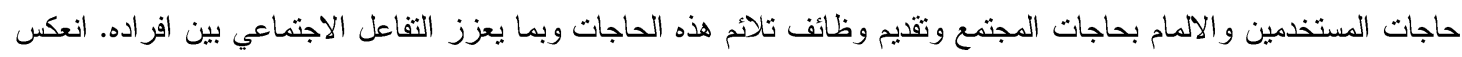
ذللك في عمارة المسجدالمعاصر إذ عبر عن خواص التصميم المستدام، فالمسجد ذو طابع مؤسساتي متعلق بالجانبين العقائدي و الاجتماعي إذ يمثل مؤسسة مركزية ونواة اجتماعية هدفها نتظيم امور المجتمع وادارة الحياة. تمنل النمط الاولي للمسجد

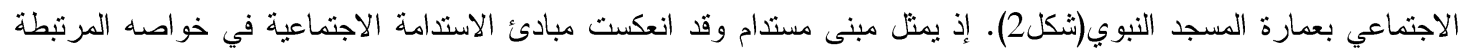
بالجانب التخطيطي، فكانت الموائمة وتلبية حاجات المجتمع والتكاملية مع السياق المحيط هي السمة البارزة لنمطه المرن كما انه يمثل فضاءاً متتفساً يسمح بتعزيز التفاعل الاجتماعي. واكدت الدراسة ان عمارة المسجد الاجتماعي عمارة سياقية تكتسب وجودها

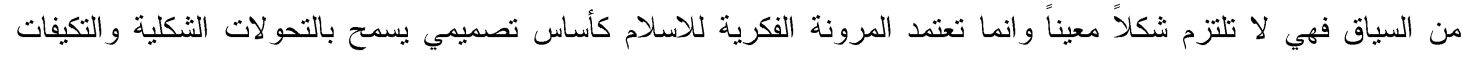
السياقية [18]. بذلك فالموائمة وتلبية حاجات المجتمع والتكاملية مع السياق المحيط وإيجاد فضاء متنفس يعزز التفاعل يعد اولوية اساسية في تحقيق النمط الاجتماعي للمسجد. 2-2 الار اسات العملية المتعلقة بعمارة المسجد والاستدامة الاجتماعية :أثنرت هذه الدراسات تعالقها مع تفسير النمط الاجتماعي للمسجد عبر تحليلها لمجموعة من المشاريع التي توظف مؤشرات الاستذامة الاجتماعية المعتمدة على دورها الوظيفي الثمولي علاوة عن دور ها في صناعة المكان.

Alice Sabrina, Ismail, nurul \& Athiqah, Baharudin اسةراسة

Communal Mosques: Design functionality towards the development of sustainability for community

ركزت هذه الدراسة على الوظيفة الثاملة ونوعية الفضاءات التي تعزز التفاعل ضمن المسجد المعاصر كمنطلب

اساسي لموائمة حاجات المجتمع المعاصرة وذلك في مواجهة العديد من المساجد المعاصرة التي صممت كثكل مركزي. وعد هذا لعزي المنطلب الإطار الموجه في تصميم المسجد الاجتماعي المستقبلي. فالمسجد يعد المحفز الاساسي في عمارة المجتمع الاسلامي عبر تحقيق التتاغم. وجاءت الفضاءات الاجتماعية بوظائف متعددة ضمن المسجد معبرة عن منطلبات التتاغم. ويعد المسجد النبوي نموذجاً بارزاً للنمط الاجتماعي الذي لايمثل مكان مقد خاص بالعبادة ولكن ايضاً لتامين الفعاليات الاجتماعية و لاغر اض اجتماعية

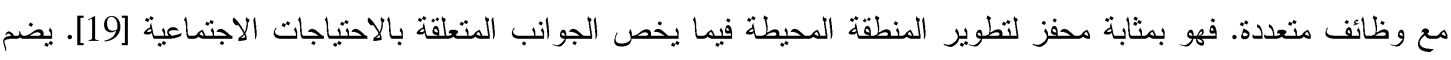

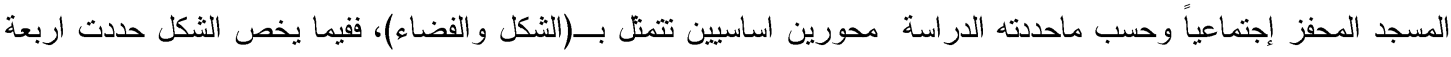
نقاط اساسية تتعلق به(الو اجهة Façade وتضم فتحات تعزز العلاقة مع السياق، التوقيع Setting ويركز على العلاقة التكاملية مع السياق المحيط ويكون ضمن مركز الفعاليات الاجتماعية مع نوفير نقاط وصول سهلة من والى المسجد مزودة بمداخل فئل فئل ومنافذ

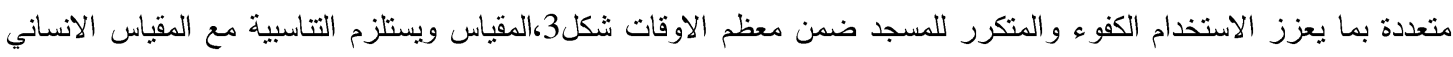

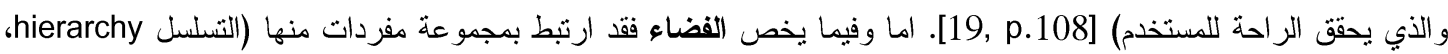
النتظيم الخاص bulding layout، نمطية التجميع zoning). كما ان تحسين نوعية الحياة للمستخدمين بعزز من التفاعل بينهم وبرز عبر ادخال الجانب الطبيعي ضمن الفضاء،فكان العبادة مفعم بعناصر الطبيعة [19, p.120].

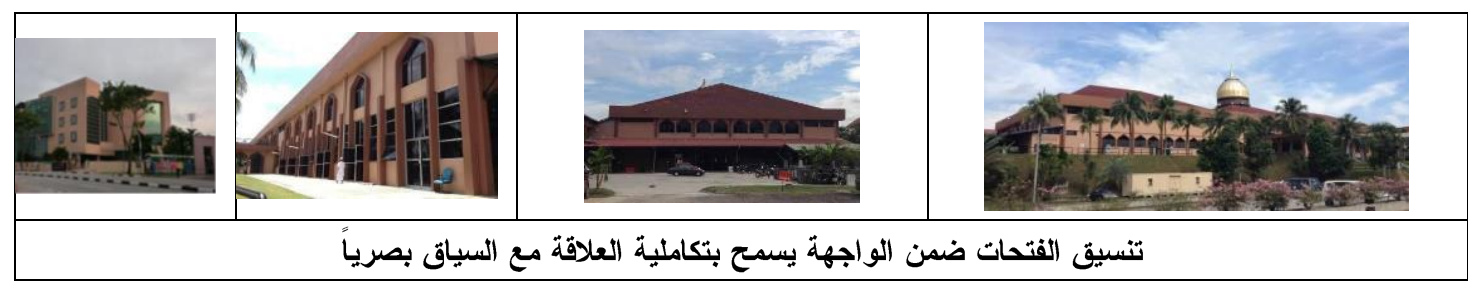




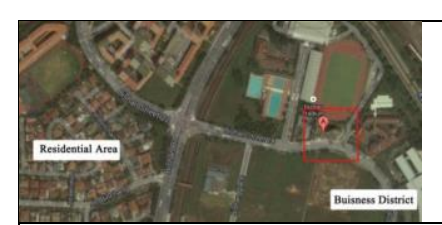

التوقيع ضمن مراكز الاكتظاظ البشري الحيوي

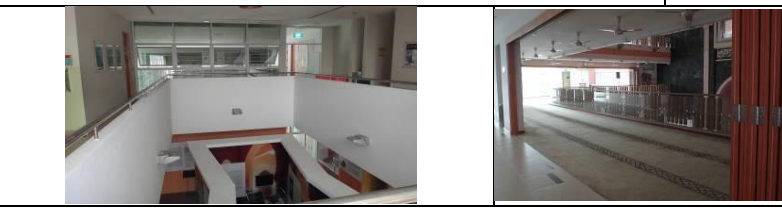

المقياس الآساني ضمن الفضاء الأاخلي وتوقيع الفعاليات الوظيفية

بمعزل عن قاعة الصلاة وضمن مستويات عمودية

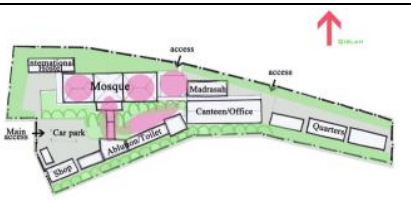

التوقيع-التنظيم الخاص لعلاقة المخطط بالسياق يوضح نقاط الوصول وتوقيع الفضاءات ذات الوظائف المتعددة.

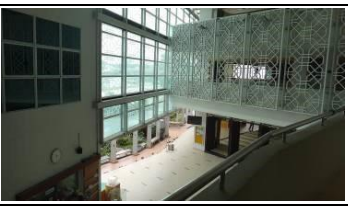

التسلسل في توقيع الفعاليات وحسب درجة خصوصيتها من العام الى شبه العام الى الخاص

شكل 3 يوضح مؤشرات المسجد المحفز إجتماعياً من نموذجين خاصين بالمساجد في ماليزيا

ووفق ما سبق فالمسجد يعد محفز أساسي لعمارة المجتمع الاسلامي عبر تلبية احتياجاته ويهدف الى تحقيق بيئة اجتماعية

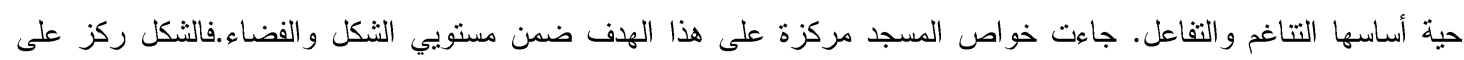
التوقيع الفعال في تعامله مع السياق عبر التتاغم وسهولة الحركة بينما الواجهة ركزت على التكاملية مع السياق عبر مجموعة معالجاتها بيئياً وتتسيقياً.بينما التعدد الوظيفي للفضاء الداخلي للمسجد كان محققاً لكفاءة التشغيل وفضاء مستدام وتمت معالجتها بشكل

$$
\text { هرمي يضمن الخصوصية . }
$$

2-2-2 المشروع الفائز بجائزة الاغاخان/مسجد اور رؤوف في بنغلاش ككا: كان الاساس الفكري للانطلاق بالفكرة التصميمية هو ايمان المصممة مارينا تاباسو لئز

بان المسجد لايتعلق بفعالية الصلاة وحدها وانما هو مكان لتجمع وتفاعل الناس طو ال اليوم. فهو مكان مرحب للجميع ضمن جميع الاوقات. و انطلاقاً من ايمان المصممة بأن الابنية تعبر عن طريقة عيش ولها خصوصيتها بحد ذاتهات الها [20]. جاءت معالجاتها للمسجد بشكل يحقق العلاقة التفاعلية مع السياق وذلك عبر (التوقيع ضمن مراكز الاكتظاظ البشري، ومعالجة المدخل الذي وقع بـان

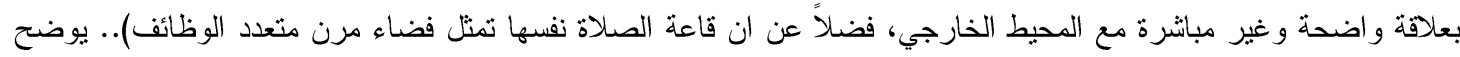
شكل (4) مستويات عمارة المسجد.
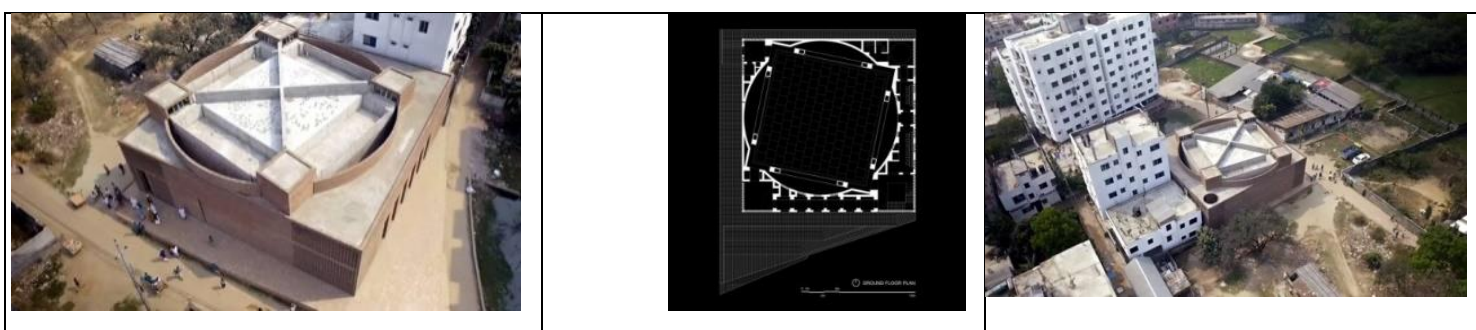

التوقيع:العلاقة التكاملية مع السياق تبرز عبر: سهولة الوصول والوضوحية مع مركزية التوقيع ضمن مناطق الاكنظاظ
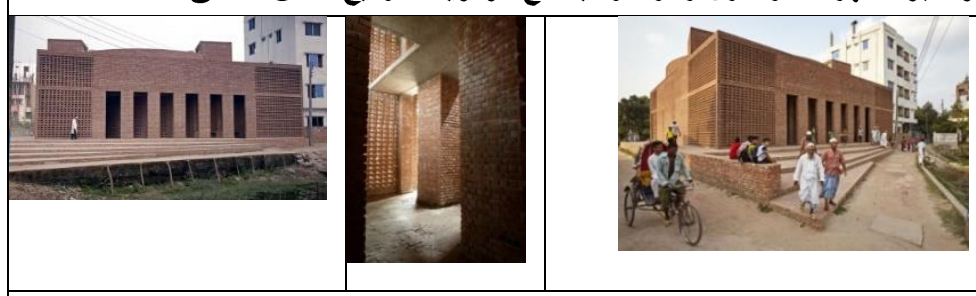

العلاقة مع السياق: التعددية في تحديد مداخل المسجد اسهمت في تعزيز

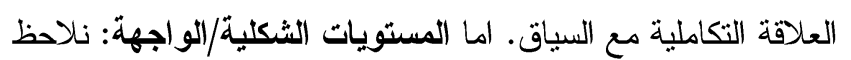

المعالجات السطحية الخارجية ذات فتحات تضمن تحقيق التو اصل الاجتماعي مع السياق المحيط..

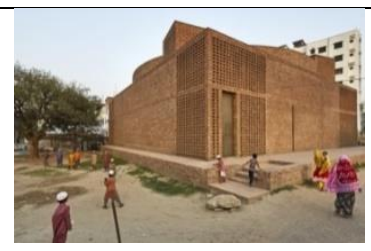

الحجم:المقياس الانساني وتوظيف المواد المحلية عززت من وصفه مسجد صديق للبيئة. 


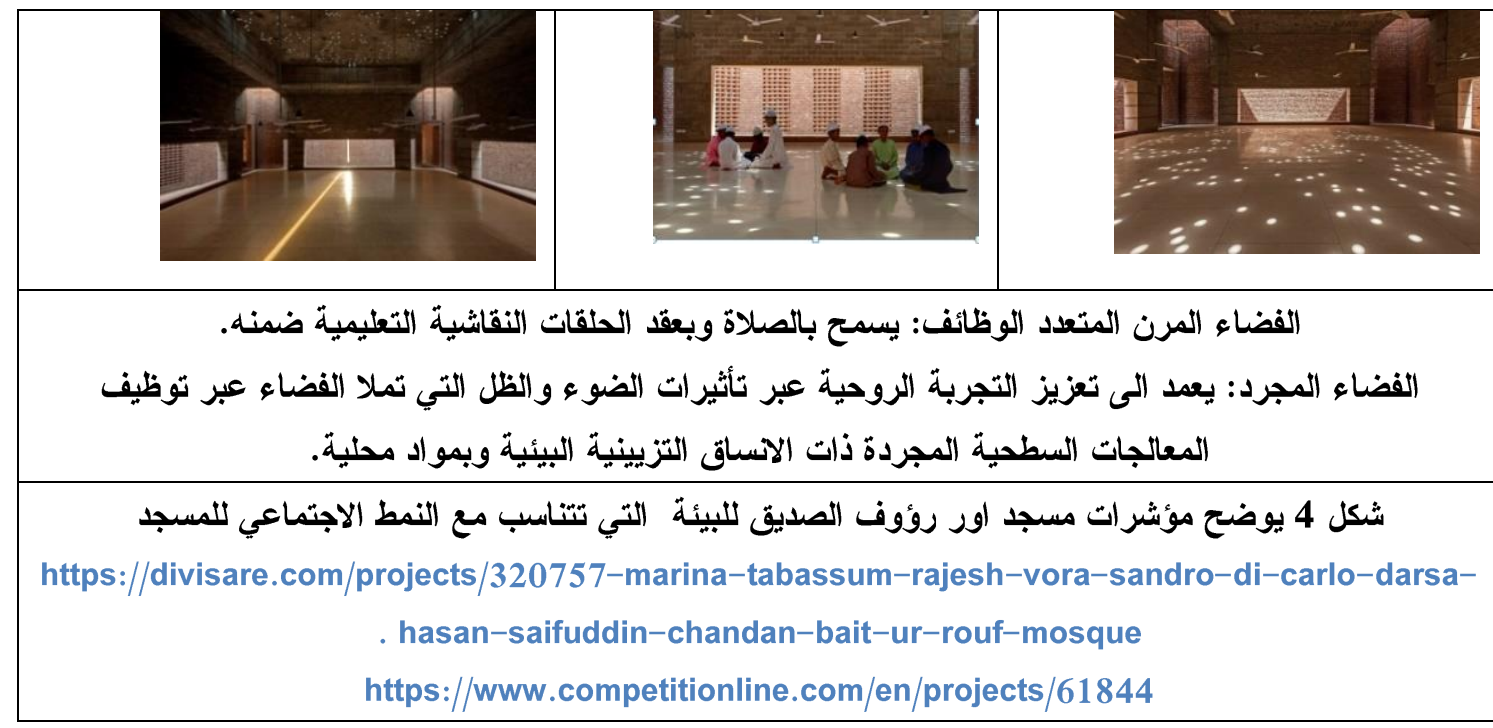

3-مناقشة الاراسات واستخلاص مؤشرات الإطار النظري:

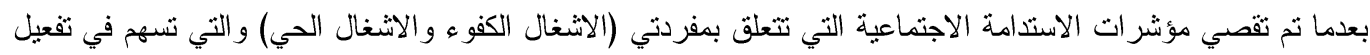

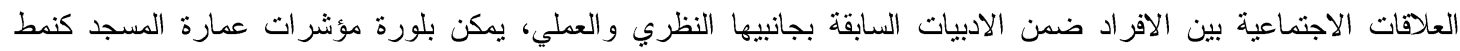

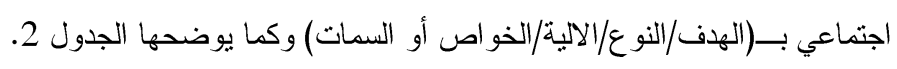
3-1 الاهداف: وتتعلق بدور المسجد في بناء المجتمع عبر تحقيق بيئة إجتماعية حية وكفو وة أساسها التتاغم و التفاعل و التو اصل بين الافر اد وبما يحقق الاثثغال الحي و الكفو و للمسجد عبر اعتماد العلاقة الفعالة و التكاملية مع السياق.

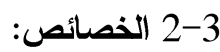

2-2-3-1الخصائص النوعية للنمط الاجتماعي للمسجد: ان نوصيف مسجد نمطاً إجتماعياً يرتبط بنوعه وتعريفه كـالمسجد (المؤسسة/الثامل/النواة/المحفز لعمارة المجتمح)، وجميعها تركز على إدامة العلاقة الاجتماعية الفعالة بين الافرادياد

$$
\text { و الجماعات. }
$$

2-2-3 الخصائص المادية للنمط الاجتماعي للمسجد: يمكن توضيح خو اصده عبر مستويات عمارة السجد و التي ترتبط بالجانب

$$
\text { النخطيطي و الثكلي و الفضائي وكالاتي: }
$$

أ-معالجات الجاتب التخطيطي للمسجد كنمط اجتماعي وترتبط بـإسلوب التوقيع ويعد محداً أساسياً محقق للاثنغال الكفوء والحي ويثترط مجمو عة منطلبات منها:

• مركزية التوقيع ضمن مر اكز الفعاليات الاجتماعية والاكتظاظ البشري فهو مؤسة مركزية ونواة إجتماعية.

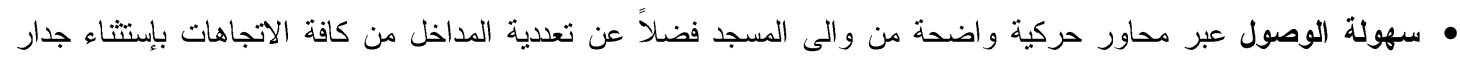

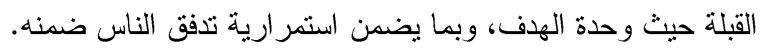

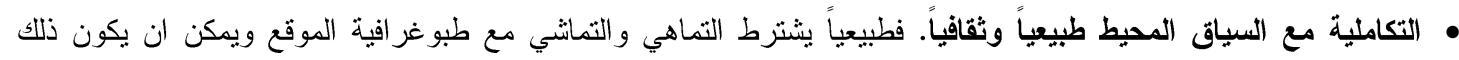

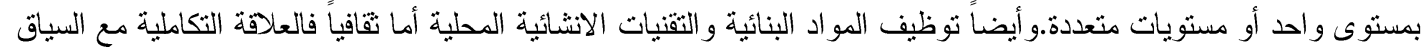

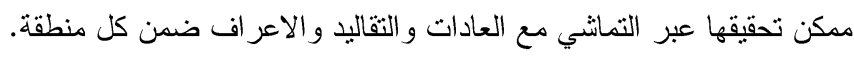
ب-معالجات الجاتب الفضائي للمسجد كنمط إجتماعي تؤثر في مكونات المسجد وتعتمد ديمومة الفعالية ضمن الفضاءات بغية

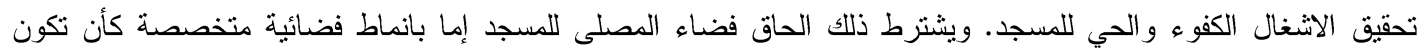

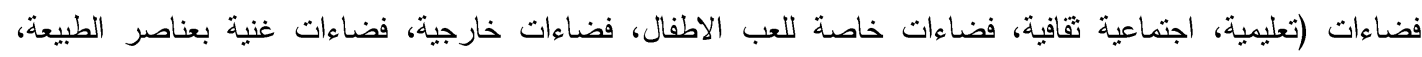

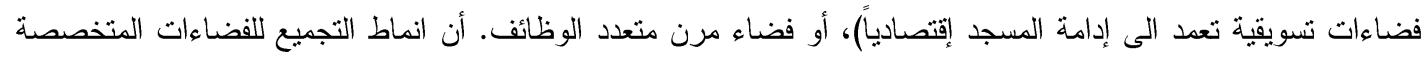

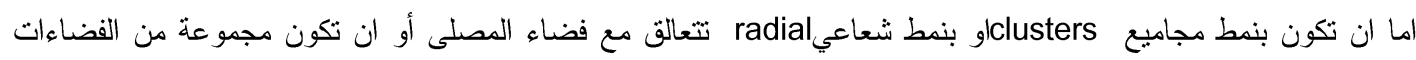
موز عة بتسلسل مندر ج وتتعالق مع فضاء المصلى اما بمستوى و احد أو مستويات متعددة. 
ج- معالجات الجاتب الثكلي للمسجد كنمط إجتماعي وترتبط بمجموعة مفردات منها (حجم المسجد ومقياسه، تفاصيل الواجهة

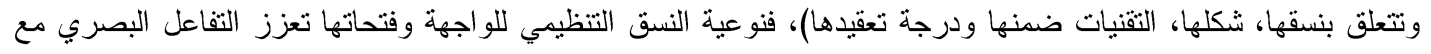

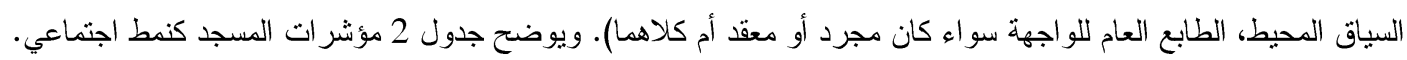

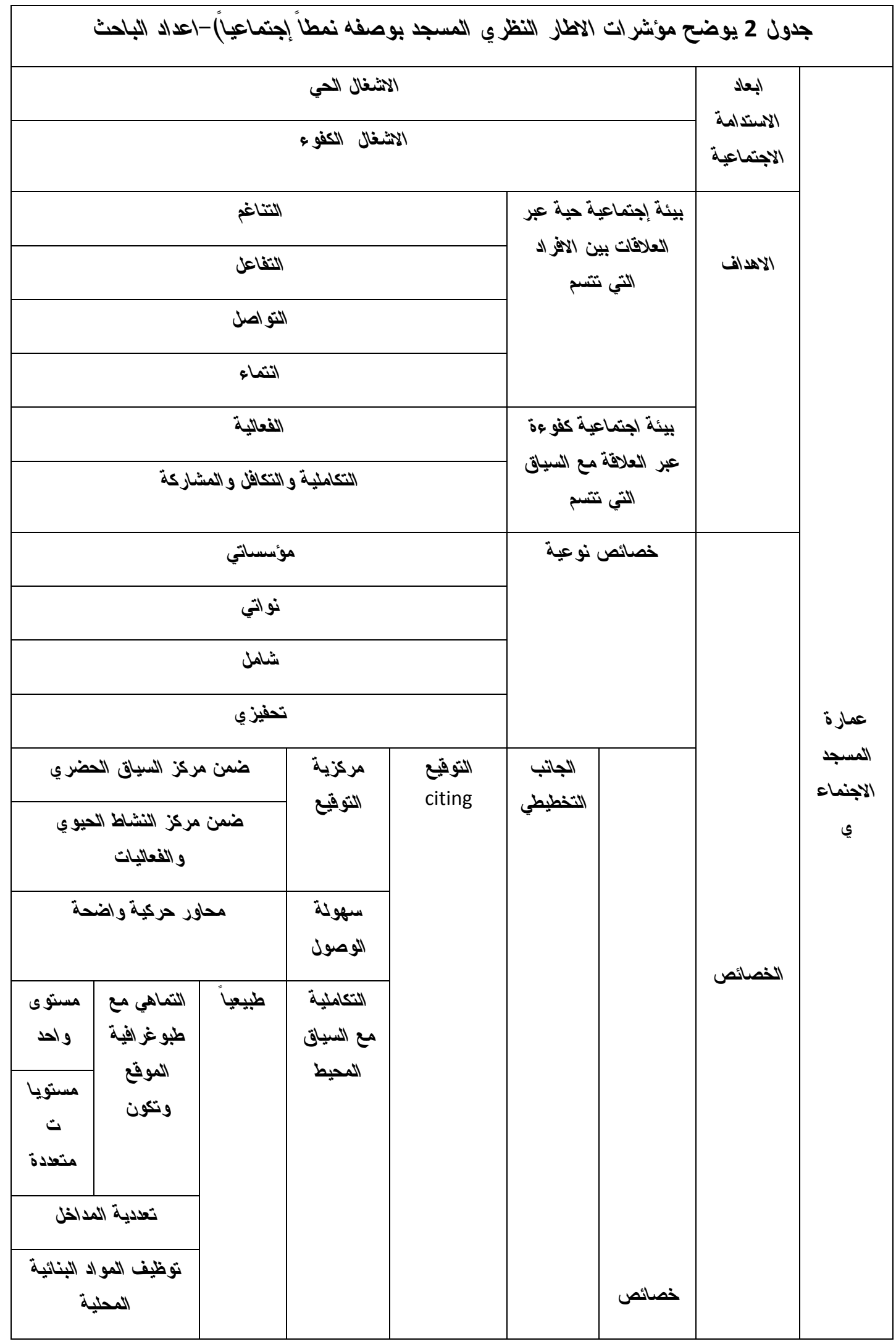


Journal of University of Babylon for Engineering Sciences, Vol. (27), No. (2): 2019.

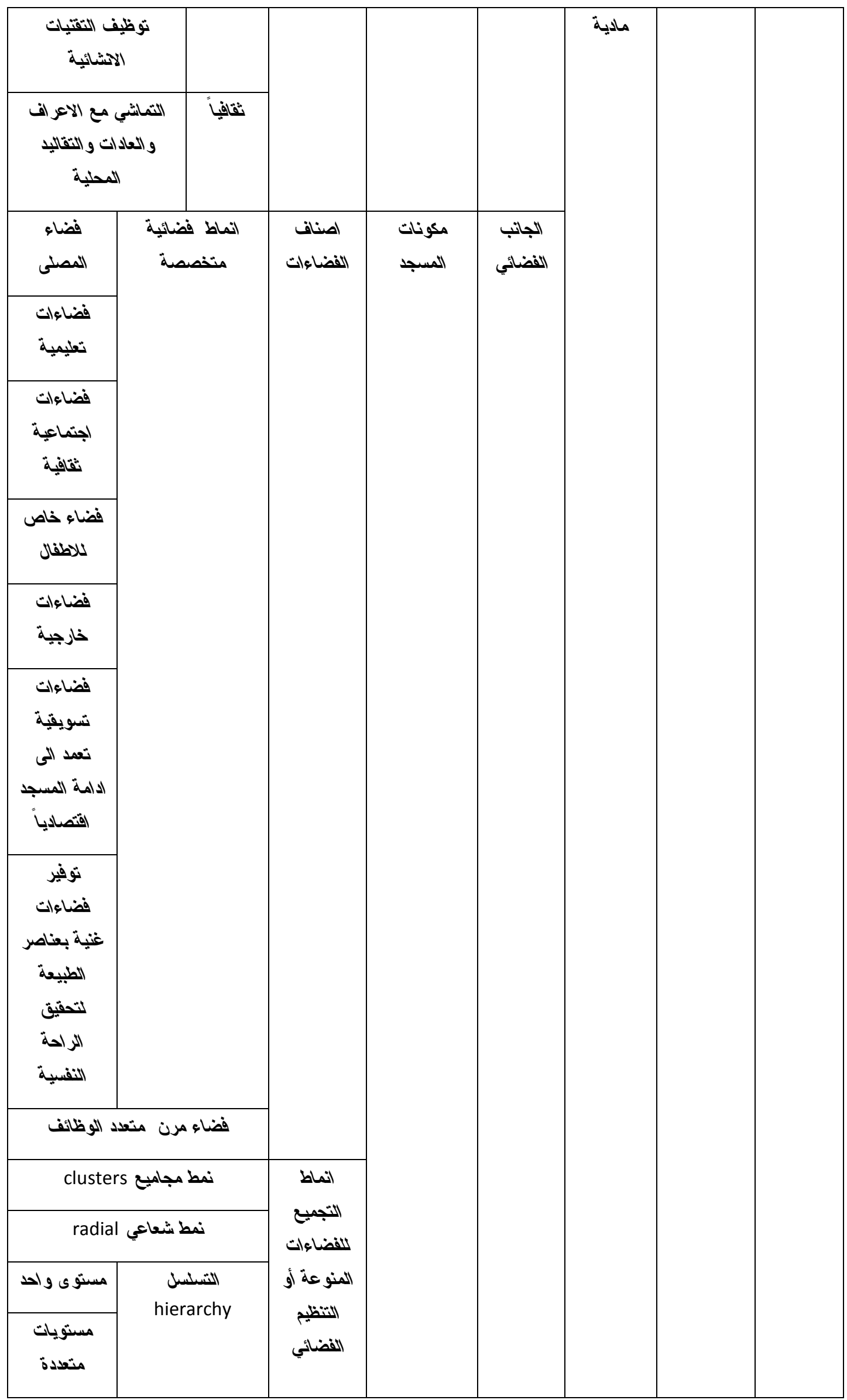




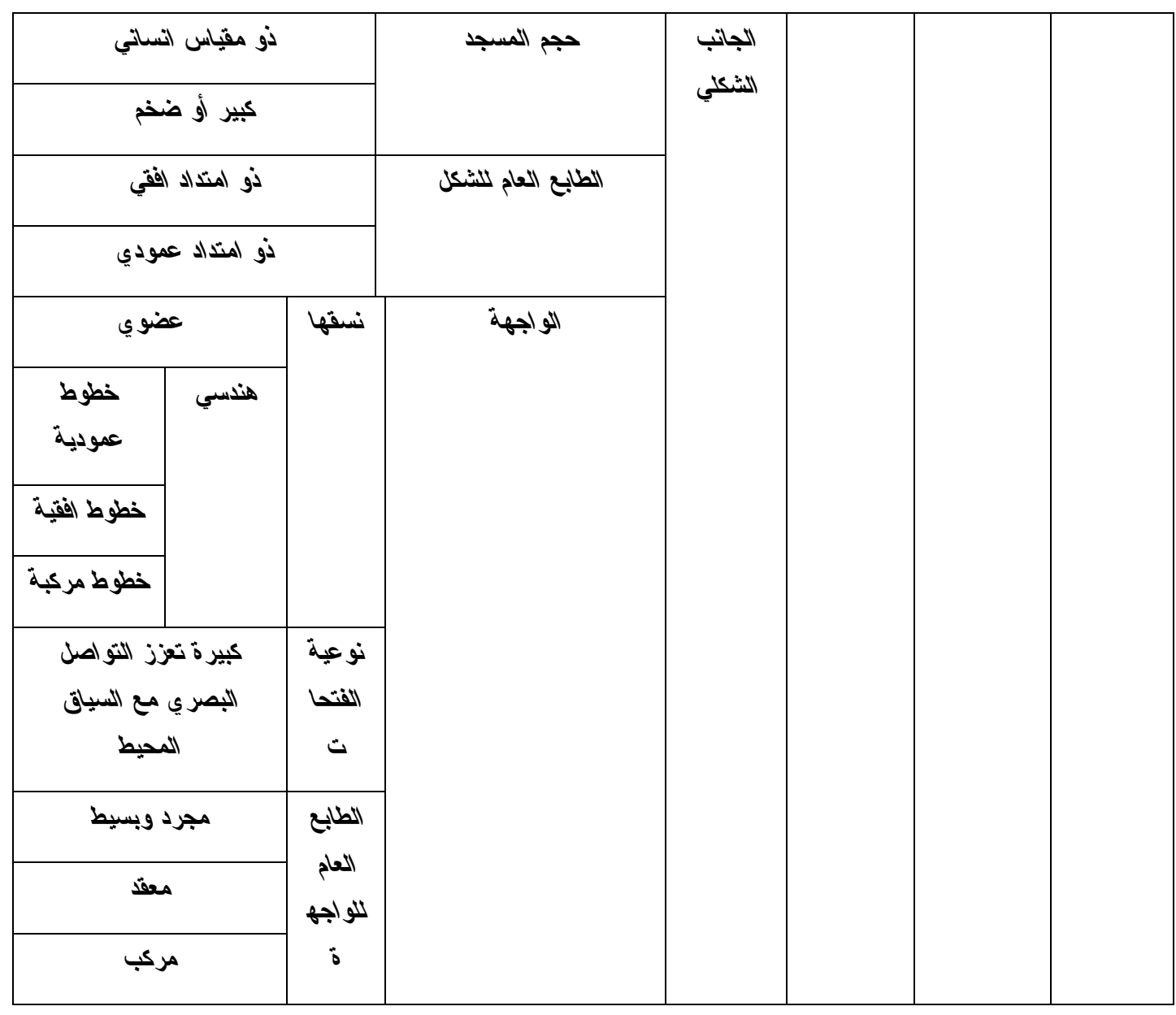

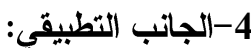

بعد ان نم تحديد مؤشرات النمط الاجتماعي للمسجد ضمن جدول 2 سيصار التحقق من فرضية البحث، إذ سيتم اختبار

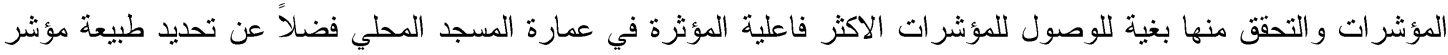

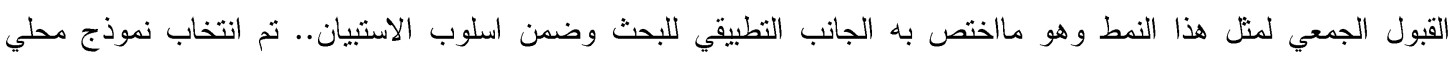

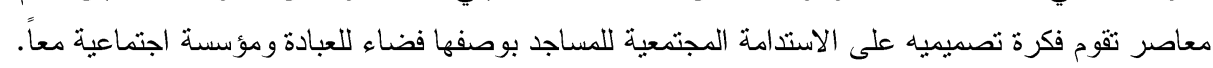

\section{4-1 2 - 1 مسجد التون في اربيل 2015:}

جاءت تسمية المسجد تمانبياً مع الكلمة التركية التون بمعنى الذهب، وجاء تأسيسه إنطلاقاً من فهمه كمؤسسة دينية

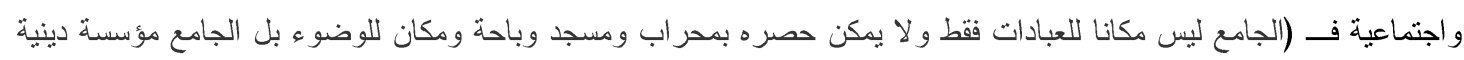

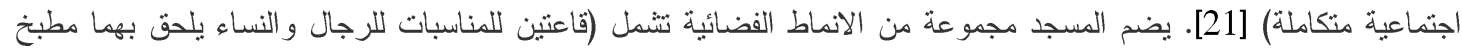

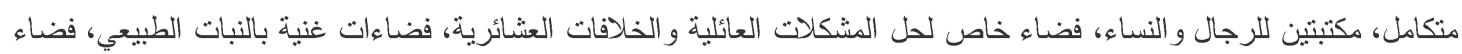

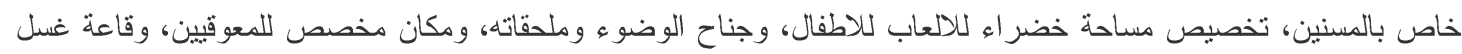

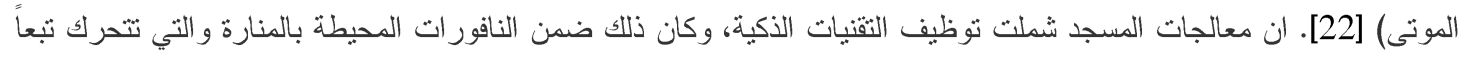

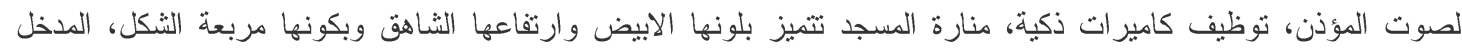

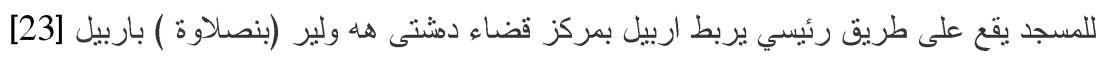

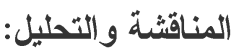

للوصول الى نتائج تفصيلية خاصة بمؤشرات المسجد الاجتماعي ولصعوبة اختبار كافة المؤشرات ضمن النموذج المحلي،

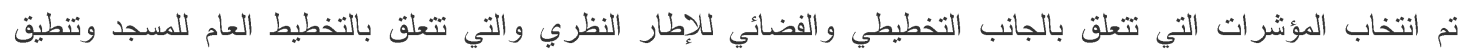


الفعاليات ضمن التنظيم الفضائي الخاص به شكل 5. نم الاستبيان لهذه المؤشرات ومفرداتها وحسب جدول 3 لتحديد المفردات الفاعلة ضمن المسجد المحلي وتحديد طبيعة المعيار المحدد لقبول هذا النمط ضمن عينة تنكون من 100 شخص، تم تقسيمه بنسب 60\% منهم من المختصين بالعمارة الاسلامية واصحاب الاختصاص الاقيق و25\% من طلبة المرحلة الرابعة و الخامسة لقسم هندسة العمارة و15\% من عامة المجتمع. حسب جدول 3

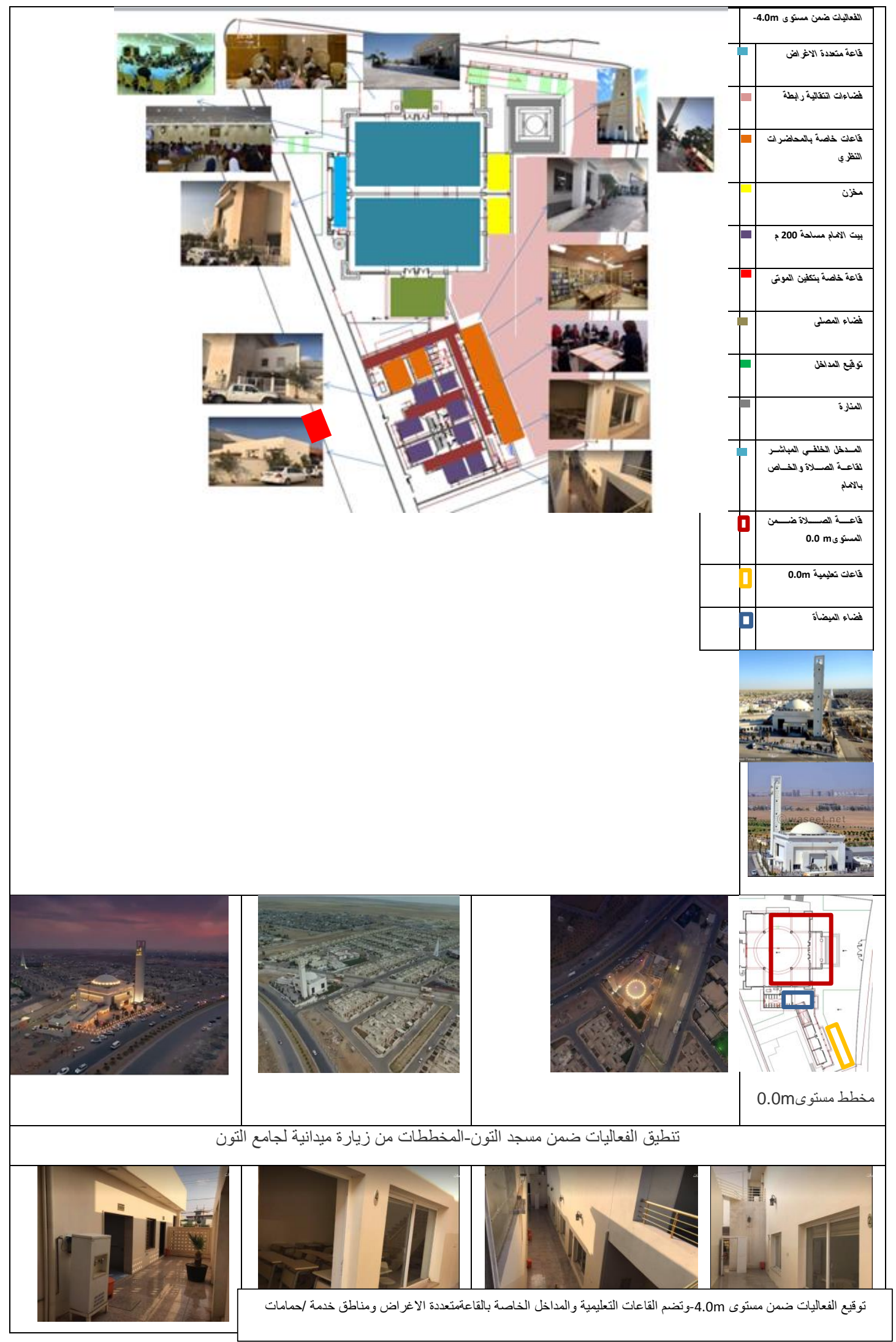




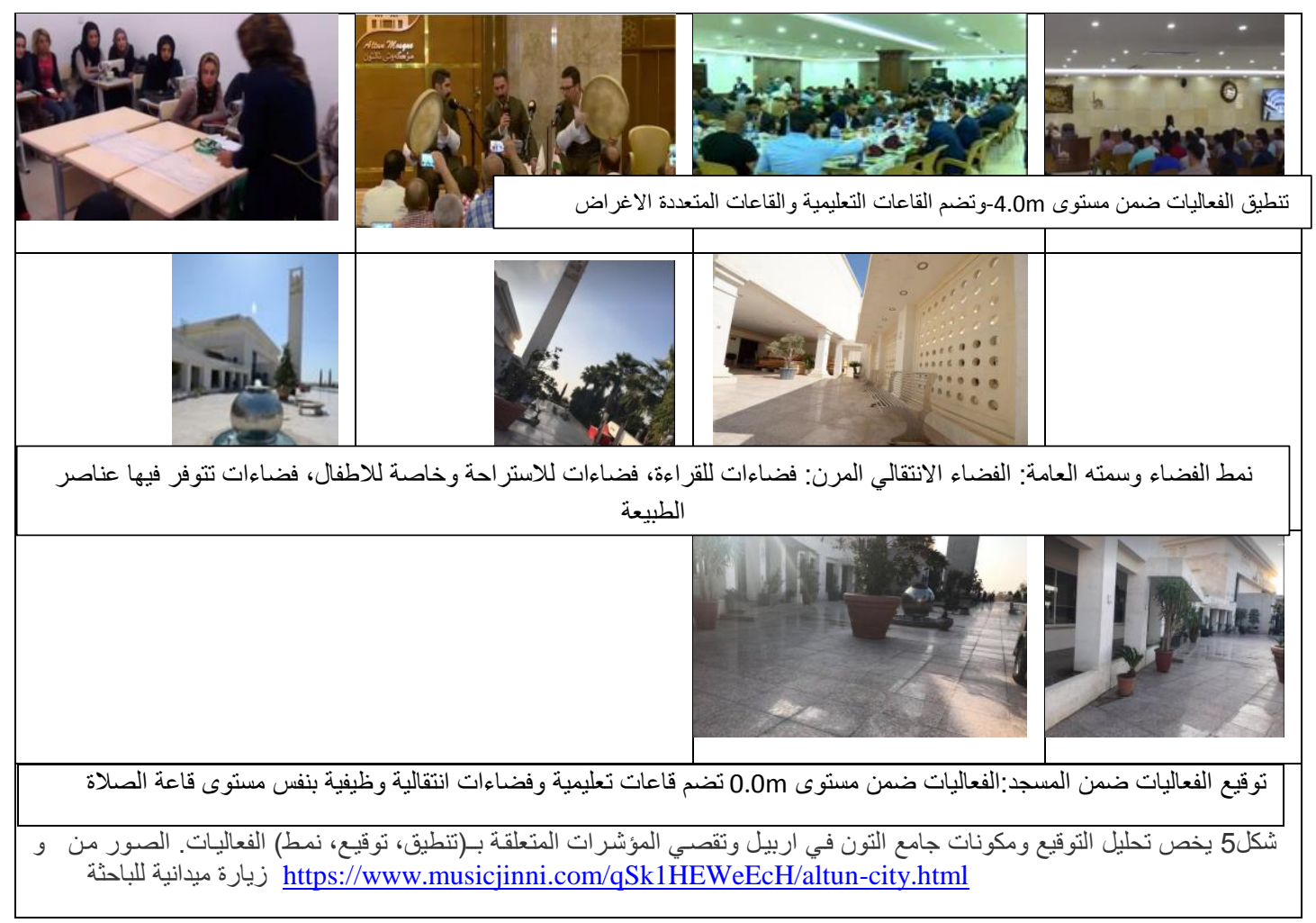


Journal of University of Babylon for Engineering Sciences, Vol. (27), No. (2): 2019.

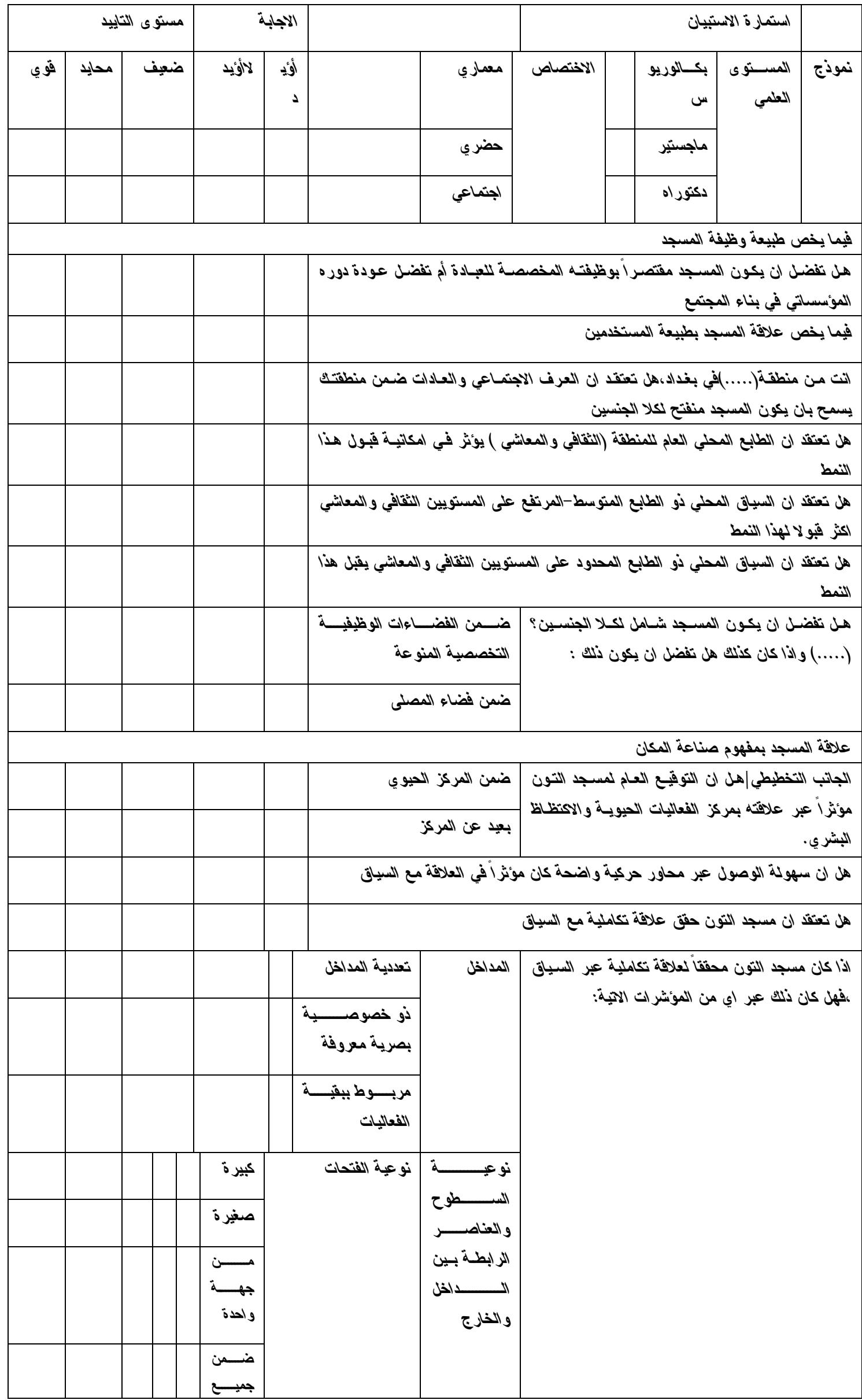




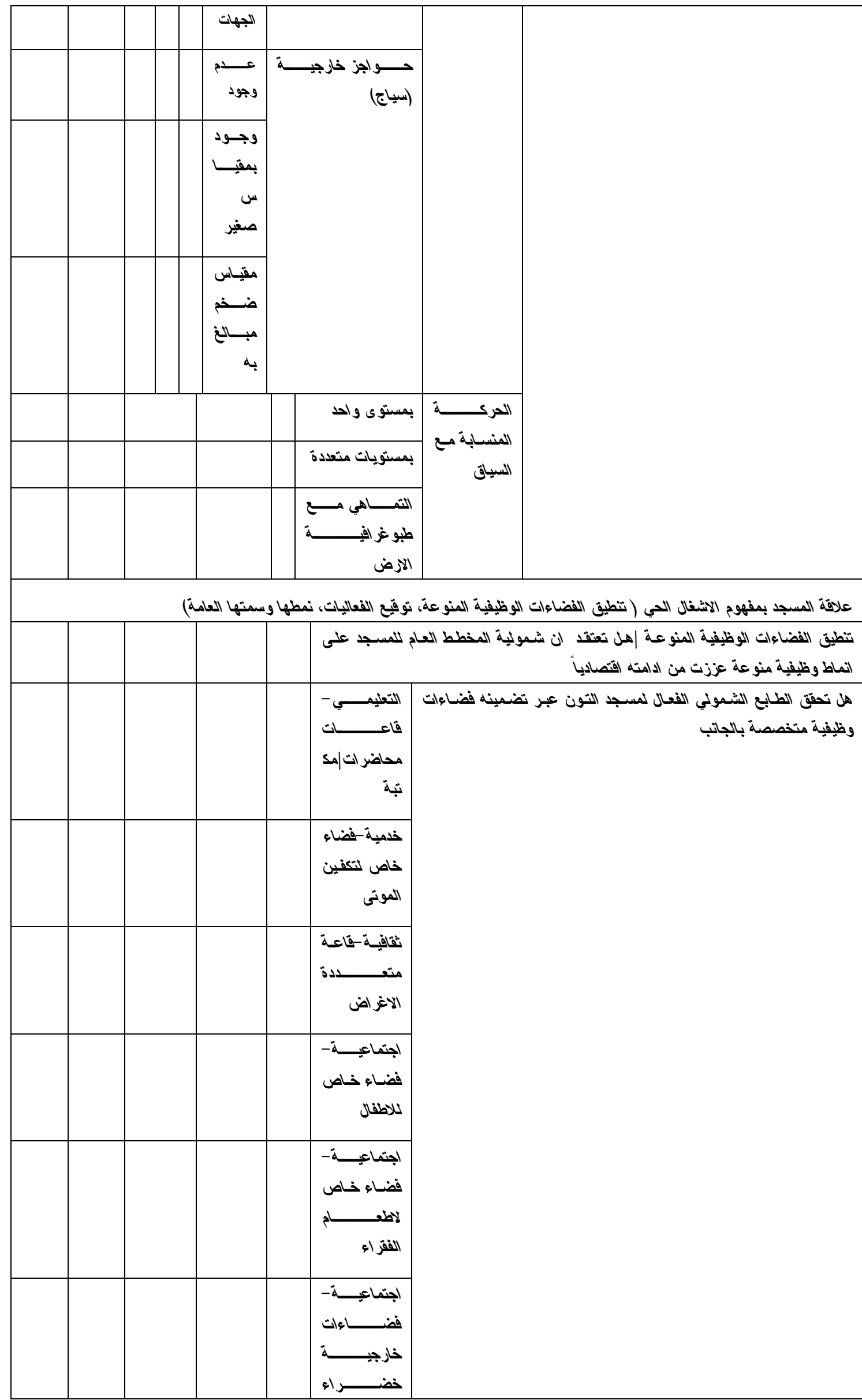




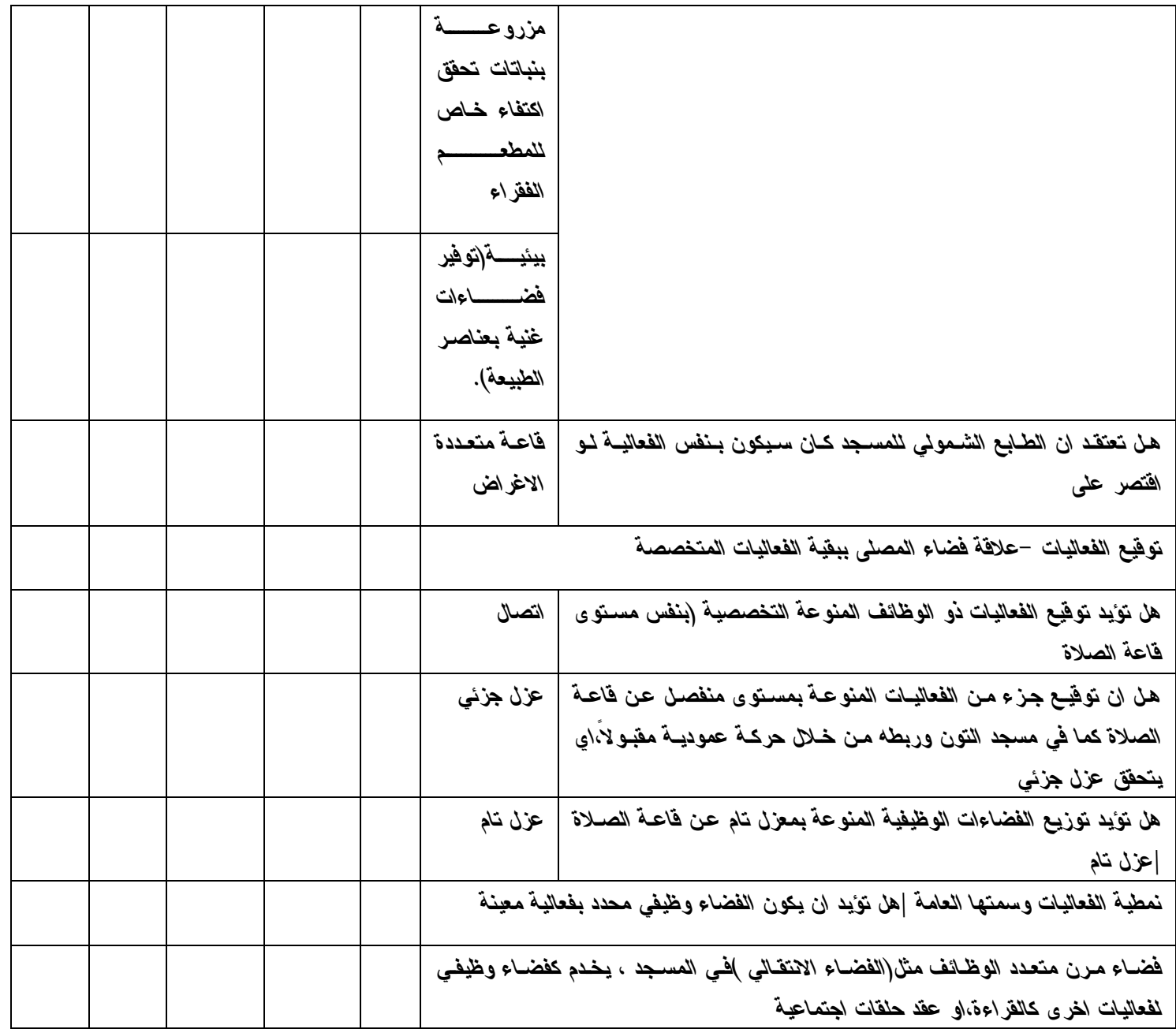

النتائج: اوضحت نتائج الاسنيبان ان مسجد الثنون و على الرغم من فهمه وتصميمه كمؤسسة إجتماعية وعلى الرغم من الثناييد القوي

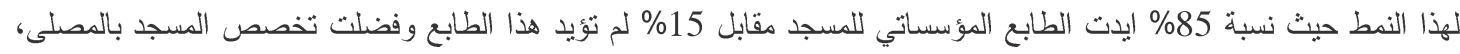

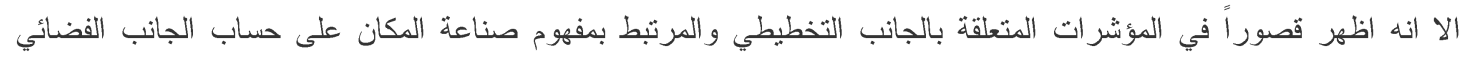

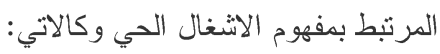

فيما يخص المؤشرات المرتبطة بالجانب التخطيطي المرتبط بمفهوم صناعة لمكان، اظهرت النتائج ان نسبة 80\% من وند

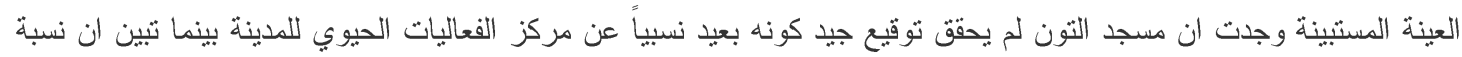

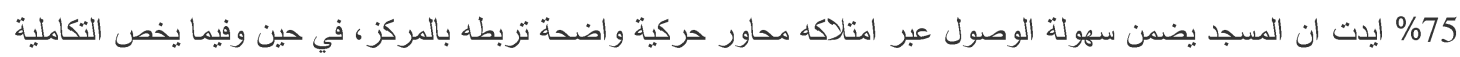

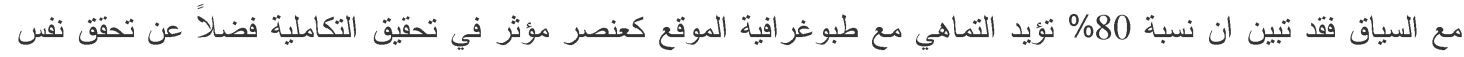

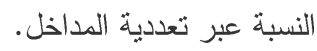

في حين وفيما يخص المؤشر ات المرتبطة بالجانب الفضائي المرتبط بمفهوم الاثشغال الحي، بينت نتائج الاستيان ان نسبة

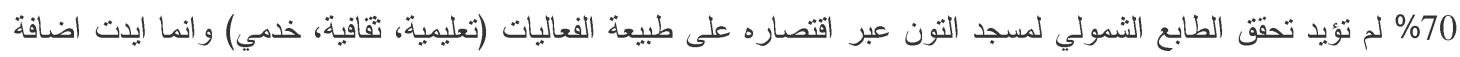

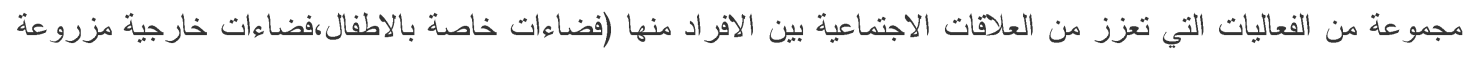

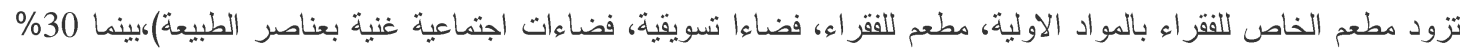
ايدت تحقق الطابع الثمولي وبشكل قوب. تنطيق الفعاليات شكل6 6

فيما يخص توقيع الفضاءات الوظيفية المتخصصة وعلاقتها بقاعة الصلاة، بينت نتائج الاسنيان ان نسبة 75\% أيدوا عزل

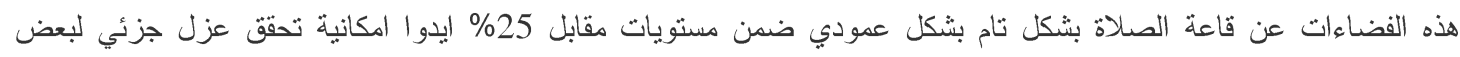
الفعاليات دون سواها اذ ايدو امكانية وجود علاقة بين قاعة الصلاة والفضاءات التعليمية كما في مسجد التون. نوقيع الفعاليات شكل 
اوضحت نتائج الاستيان ان 45\% أيدوا ان تككن الفضاءات الانتقالية (الممرات)فضاءات وظيفية مرنة (مككن ان تكون

خاصة بالقر اءة،فضاءات خاصة للعب الاطفال،فضاءات خاصة بالطعام،) وبشكل قوي بينما 35\% ايدو ان انكون فضاءات خاصة

كتوسعة لقاعة الصلاة في حين ان 20\% لم يؤيدو اتوظيف هذه الفضاءات وكان تقييمه لها بشكل محايد نمطية الفعاليات شكل6

اوضحت نتائج الاستبيان ان 85\% من المستبينين أيدوا تفعيل الطابع المؤسساي للمسجد بشكل قوي مقابل 15\% أيدوا

اقتصار المسجد على فعالية الصلاة.

تباينت نسبة قبول المسجد المؤسسة ضدن المجتمع،اذ تبين انها تعتمد على الطابع التقافي و المعاثي العام للمتلقي ،فالمناطق

ذات الطابع الثقافي والمعاشي(المتوسط اظهرت تاييدها لهذا النمط بنسبة 35\%بينما المناطق ذات المستوى المرتفع) اظهرت

تأييدها بنسبة 45\% بينما المناطق ذات الطابع التقافي والمعاثي المحدود اظهرت تأييدها لهذا النمط بشكل ضعيف وبنسبة

620

تبين مما سبق قصور المسجد المحلي وعدم شموليته في بعض الجوانب و المؤشرات المحقة للمسجد الاجتماعي و التي سبق وان تم التوصل اليها ضمن جدول 2، فعلى الرغم من تصميمه كمؤسسة اجتماعية الا انه لم يركز على التوقيع كمؤشر اساسي

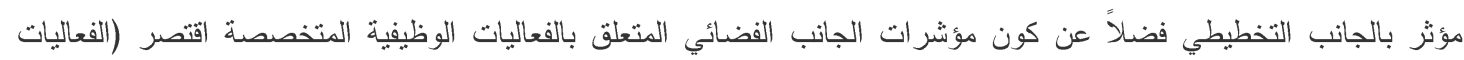

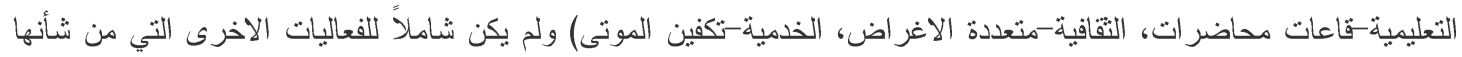

تعزيز التفاعل الاجتماعي بين افراد المجتمع.

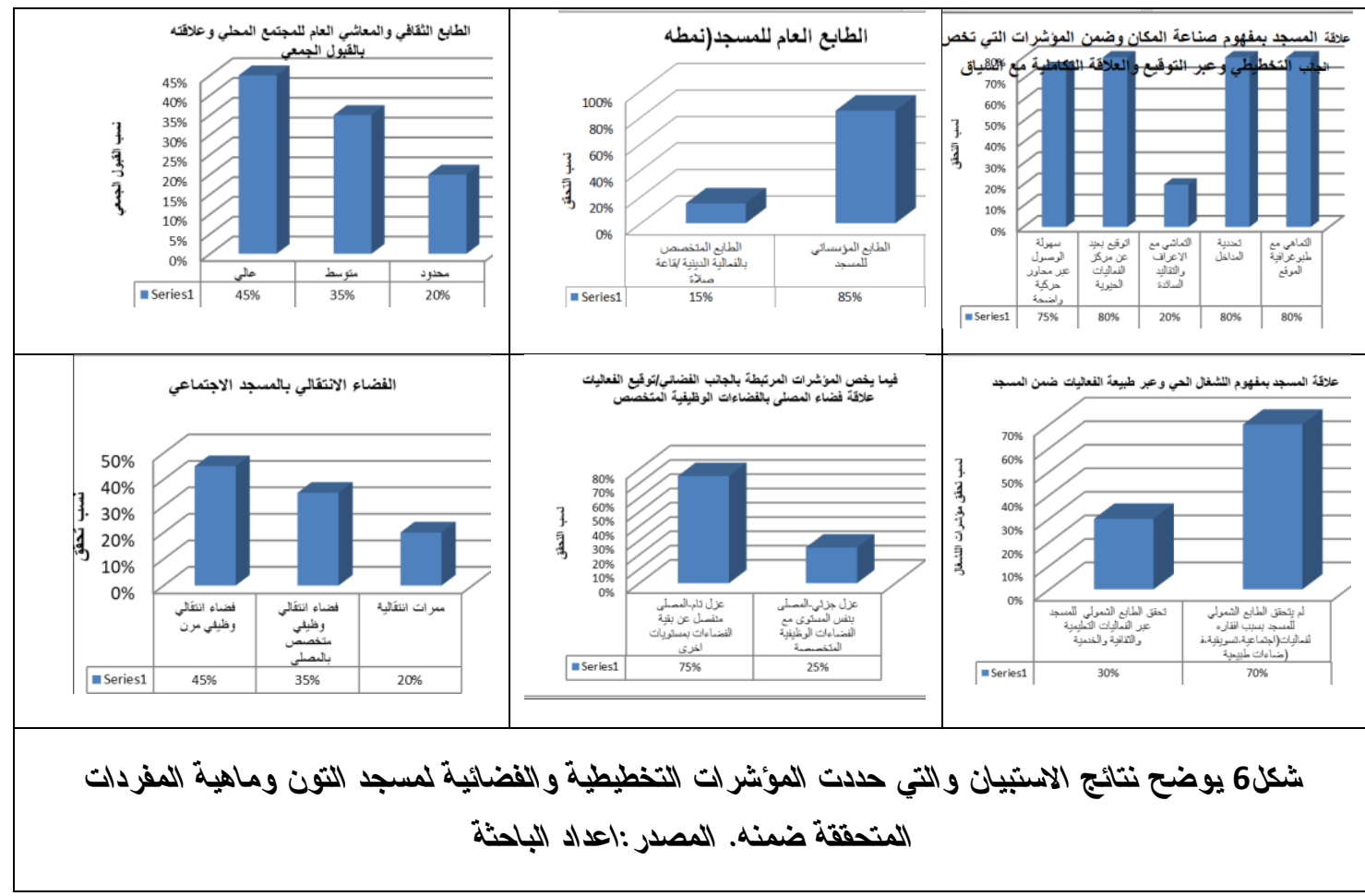

| الاستنتاجات:

يمكن تعريف المسجد الاجتماعي بوصفه نمطاً عقائدياً يتسم بحضوره الدائم نتيجة علاقته التفاعلية مع السياق الاجتماعي وبما يضمن استمر ارية تدفق الناس ضمنه.

تتمثل ابعاد الاستدامة الاجتماعية في عمارة المساجد عبر دوره المؤسساتي الثنامل ومايحققه من اشغال حي وعبر دوره في صناعة المكان اللذين يؤشران خو اص الاستدامة الاجتماعية المؤثرة في تحديد خواص عمارة المسجد الاجتماعي دورة الاعي 
تتعلق مؤشر ات المسجد الاجتماعي بالجو انب التخطيطية و الثكلية و الفضائبة.. ففيما يخص الجانب التخطيطي ارتبط بسياسة (التوقيع والتخطيط العام و العلاقة التكاملية مع السياق). اما الجانب الفضائي فتعلق بطييعة الفضاءات الوظيفية (تنطبقها) وتوقيعها ونمطها وسمتها العامة.

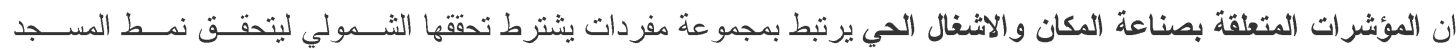

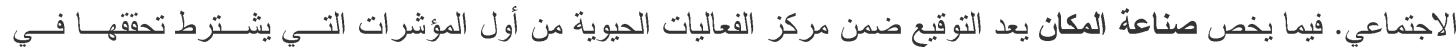

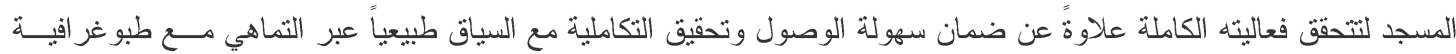
الموقع وتعددية المداخل. اما الاشغال الحي فقد ارتبط بالمؤشرات التي تخص الجانب الفضائي وتوصل البحث الى تبويبها ضمن:

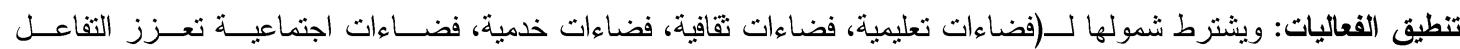
الاجتماعي كأن تكون فضاءات مخصصة للاطفال، مناطق خضر اء مزروعة يستفاد منها في تاويل مطعم خاص للفقر اء، فضــاءات

تسويقية، (لاجية

توقيع الفعاليات: توصل البحث الى ان توقيع الفضاءات الوظيفية المتخصصة يتم بمعزل عن قاعة الصلاة وبشكل ثام، اذ ممكــن ان يتم عبر مستويات عمودية او مجمعات افقية.

نمطية الفعاليات وسمتها العامة:توصل البحث الى ان المرونة تعد السمة العامة التي تضفي امكانية تفعيل الفضاءات لتكون فضـــاء

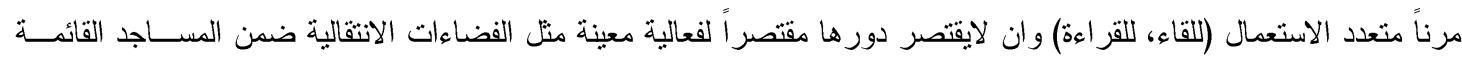
ممكن توظيفها كتوسعة لقاعة الصلاة او فضاءات للقر اهة و اللقاء.

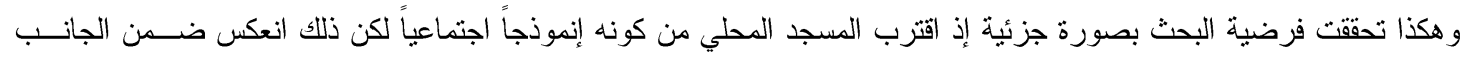

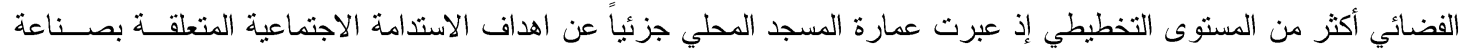

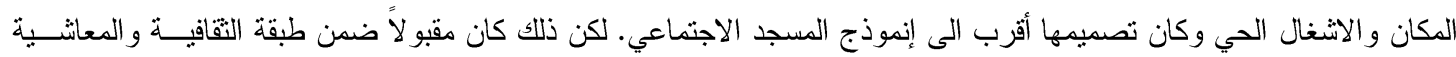
المرتفعة كما وضحت نتائج الاستييان على الرغم من كونه لايمنل نمطاً جديداً ضمن عمارة المساجد المعاصرة وانما تمثلك امتـداداً للاور الوظيفي للمسجد النبوي

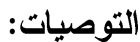

كيوصي البحث بتبني مفهوم المسجد الاجتماعي و اعتماد مؤشر اته التي تتعلق بفهمه كمؤسسة اجتماعية تـــتبط بابعـاد الاســتـامة الاجتماعية المتعلقة بمفاهيم الاشغال الحي وصناعة المكان كونه مسؤؤل عن تطوير وادامة المجتمع.

-تعزيز الدر اسات المستقبلية عن الجوانب المرتبطة بالمسجد الاجتماعي والخاصة بــ(الجو انب التخطيطيــة، الفضــائية والثـــلية) لتحديد إطار موجه للعملية التصميمية الخاصة بهذا النمط من العمائر .

-اجر اء در اسة تحليلية مقارنة بين نمط المسجد الاجتماعي وتطبيقاته ضمن الو اقع (المحلي و العربي و العالمي) لتقصي الجوانب التي ممكن الاستفادة منها ضمن كل سياق في اغناء السياق الاخر على ان لايشكل تعارضا مع مبادئ الثريعة الاسلامية.

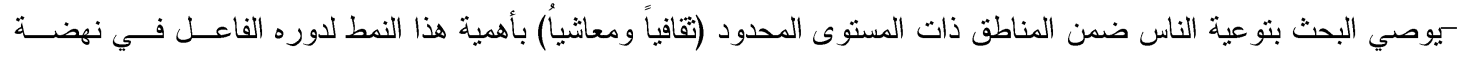
المجتمع ضمن النطاق المحلي الضيق ويكون ذلك عبر إقامة ندوات وتتريعات خاصة دئة

\section{CONFLICT OF INTERESTS.}

- There are no conflicts of interest.

[1] عيد ،أ.د. محمد عبد السميع و القاضي د.شوكت محمد لطفي و م.سارو، وائل حسين يوسف ،"دور عمارة المساجد في تأصيل مفاهيم الاستدامة(مفهوم الترشيد) في المدن العربية المعاصرة" تحت محور الاطار العملي:العمارة في العالم العربي والتكنولوجيا ،مفاهيم العمارة الخضر اءه وتقنيات الاستدامة البيئية:امكانيات التطبيق في العالم العربي، 2016، صنية

[2]Hancock, Trevor, "Social Sustainability"2008 


$$
\begin{aligned}
& \text { [3] نعمة، صبا جبار وحميد، شيماء ، "اليات تحقيق الاستدامة الاجتماعية في البنية الحضرية التقليدية (حالة دراسية في مركز مدينة }
\end{aligned}
$$

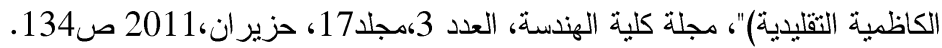

$$
\begin{aligned}
& \text { [4]هينار ابو المجد خليفة، "تصميم الفر اغات العمر انية لتحقيق الراحة الحرارية باستخدام التقنيات الحديثة للتحكم المناخي"، رسالة }
\end{aligned}
$$

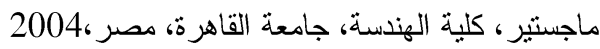

$$
\begin{aligned}
& \text { [5] حسين، شيماء حمبد، "تطوير مدينة بغداد عمرانياً"، الطبعة الاولى، دار الاحرف العراقية للطباعة و النشر،بغداد- }
\end{aligned}
$$

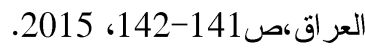

$$
\begin{aligned}
& \text { [6]لاتوش، سيرج، ترجمة : البير خوري، "تحديات - التتمية من وهم التحرر الاقتصادي الى بناءء مجتمع بديل" ، الثركة العالمية } \\
& \text { للكتاب، لبنان،2007. } \\
& \text { [7] إسماعيل، علا محمد سمير،" در اسة تحليلية لتصميم المسكن في العمارة الإسلامية في ظل مفاهيم التصميم الحديثة"، كلية الفنون } \\
& \text { التطبيقية، جامعة حلوان،2010 }
\end{aligned}
$$

[8] Dia Nema and Emad Mehdi "The Impact of Social Factors in the Planning and Architecture of Arab and Islamic Cities", 2011.

$$
\text { 1980، المصري، محمد أمين،" المجتمع الإسلامي"، دار الأرقم - الكويت }
$$

[10]Zare, R., (tasmea el faragat el aumraniay le tahqeeq el raha el harareia beistkdam el teqaneat el hadetha lltahakum el manakhei), (The Principles of Sustainable Architecture in Tradional Architecture",Arabic, Scientific Jornal of Review, 3(7) pages 640:653,shiraz,iran, 2014. www.sjournals.com

$$
\text { [11] مؤنس، حسين،" المساجد"، المجلس الوطني للتقافة و الفنون والآداب - الكويت،1981 }
$$

[12]Al-Hajla,Khalid al-Sayed Mohammed,"An Analytical syudy of the role of the mosque in bulding the social nociation in the Islamic city "(Derasa tahleleya le doaour al masjed fe benaa rabetat ai jewar ai egtemaee fe al madena el eslamia)(Arabic),scientific research,faculty of engineering ,Alexandria university.2016

[13] رؤوف،زينب حسين،"دينامية الطراز في عمارة المساجد المعاصرة "، اطروحة دكتور اه مقدمة الى قسم الهندسة المعمارية،

$$
\text { جامعة بغداد،2016، صوري }
$$

[14] Mohamad Tajuldin \& Mohamed Rasdi , RETHINKING THE MOSQUL IN THE MODREN MUSLIM SOCIETRY, ITBM- Institute Terjemahan \& Buku Maloysia, Kula Lumpur, 2014 , p.201

[15] Belhadj, Tarshawi, (taatheer elmumarsa el egtemaaia), (The Effect of Social Practice on Urbanization), Arabic, Journal of Human Sciences, Fifth Year, Issue 36,p.8, 2008.

[16] bin muhammad ,muhammed fakhar ,"Mosque as a multifunctional institution:case study of two community mosques within the neighbourhood of the modernmalaysian society",2012. nur/https://www.slideshare.net/fahaska/mosque-as-a-multifunctional-institutio) muhammed fakhar,

$$
\text { [17] عثمان، محمد عبد الستار ، "المدينة الاسلامية"، دار الافاق العربية. }
$$

[18] OMER, SPAHIC, " PROPHET MUHAMMAD (PBUH) AND THE HOUSING PLANNING AND DEVELOPMENT IN MADINAH، "2015, p.21,22

[19]Nayeem Asif \& Nangkula Utaberta “" REVIEW ON SUSTAINABLE AND INNOVATIVE APPROACH TOWARDS MOSQUE DESIGN IN CONTEMPORARY WORLD", 2016, p.2 https://www.researchgate.net/publication/307878209

[20] Alice Sabrina, Ismail,nurul \& Athiqah ,Baharudin "Communal Mosques: Design functionality towards the development of sustainability for community "2014, P.107 
Journal of University of Babylon for Engineering Sciences, Vol. (27), No. (2): 2019.

[21] https://divisare.com/projects/320757-marina-tabassum-rajesh-vora-sandro-di-carlo-darsa-hasansaifuddin-chandan-bait-ur-rouf-mosque

[22] https://www.baghdad-times.net/2015/06/19

[23] ww.aljazeera.net/programs/newsreports/2018/6/13/

[24] https://www.musicjinni.com/4OJo6cZcv3Z.html 